\title{
New Ti-Alloys and Surface Modifications to Improve the Mechanical Properties and the Biological Response to Orthopedic and Dental Implants: A Review
}

\author{
Yvoni Kirmanidou, ${ }^{1}$ Margarita Sidira, ${ }^{1}$ Maria-Eleni Drosou, ${ }^{2}$ \\ Vincent Bennani, ${ }^{3}$ Athina Bakopoulou, ${ }^{1}$ Alexander Tsouknidas, ${ }^{4}$ \\ Nikolaos Michailidis, ${ }^{4}$ and Konstantinos Michalakis ${ }^{1,5}$ \\ ${ }^{1}$ Department of Prosthodontics, Aristotle University of Thessaloniki, Faculty of Health Sciences, School of Dentistry, \\ 54124 Thessaloniki, Greece \\ ${ }^{2}$ Aristotle University of Thessaloniki, Faculty of Health Sciences, School of Medicine, 54124 Thessaloniki, Greece \\ ${ }^{3}$ Department of Prosthodontics, University of Otago, School of Dentistry, Dunedin 9054, New Zealand \\ ${ }^{4}$ Aristotle University of Thessaloniki, School of Engineering, Department of Mechanical Engineering, \\ Physical Metallurgy Laboratory, 54124 Thessaloniki, Greece \\ ${ }^{5}$ Division of Graduate and Postgraduate Prosthodontics, Department of Prosthodontics, Tufts University School of Dental Medicine, \\ Boston, MA 02111, USA
}

Correspondence should be addressed to Konstantinos Michalakis; konstantinos.michalakis@tufts.edu

Received 27 August 2015; Accepted 30 November 2015

Academic Editor: Carla R. Arciola

Copyright (C) 2016 Yvoni Kirmanidou et al. This is an open access article distributed under the Creative Commons Attribution License, which permits unrestricted use, distribution, and reproduction in any medium, provided the original work is properly cited.

\begin{abstract}
Titanium implants are widely used in the orthopedic and dentistry fields for many decades, for joint arthroplasties, spinal and maxillofacial reconstructions, and dental prostheses. However, despite the quite satisfactory survival rates failures still exist. New Ti-alloys and surface treatments have been developed, in an attempt to overcome those failures. This review provides information about new Ti-alloys that provide better mechanical properties to the implants, such as superelasticity, mechanical strength, and corrosion resistance. Furthermore, in vitro and in vivo studies, which investigate the biocompatibility and cytotoxicity of these new biomaterials, are introduced. In addition, data regarding the bioactivity of new surface treatments and surface topographies on Tiimplants is provided. The aim of this paper is to discuss the current trends, advantages, and disadvantages of new titanium-based biomaterials, fabricated to enhance the quality of life of many patients around the world.
\end{abstract}

\section{Introduction}

Titanium was discovered in 1791 by an amateur mineralogist named William Gregor, in magnetic iron-sand (ilmenite). This element was also identified in 1795 by the German chemist Martin Heinrich Klaproth, who named it "titanium" after the Titans in Greek mythology, the powerful sons of Earth. Pure titanium is one of the most abundant metals on Earth's crust and lithosphere, but it could not be isolated in large amount until the invention of the Kroll process by a metallurgist named William Kroll, in 1946 [1]. Post-World
War II advances enabled applications of titanium in medical surgical and dental devices.

Nowadays, commercially pure titanium (cp-Ti) and its alloys are widely used for manufacturing orthopedic and dental implants due to their superior mechanical and physical properties, such as corrosion resistance and high modulus of elasticity in tension, and their excellent biocompatibility [2]. There are four grades of $\mathrm{cp}$-Ti depending on their content to oxygen and iron [3]. Following cp-Ti, Ti-6Al-4V, which is also known as Ti6-4 and Ti-grade 5, became commonly used for biomedical applications (i.e., orthopedic and dental 
implants), because of its enhanced mechanical strength [4]. It is well known that one main reason for the excellent physical and biological properties of titanium and its alloys is the native oxide film $\left(\mathrm{TiO}_{2}\right)$ that is created spontaneously on its surface upon air exposure [5]. This film, having only a few nanometers thickness $(4.3 \pm 0.2 \mathrm{~nm}$ for the mechanically polished cp-Ti surface) [6], appears to be responsible for the chemical stability, chemical inertness, corrosion resistance, and even biocompatibility of titanium [5].

Unquestionably, much progress has been done over the years, and the survival rates of dental and orthopedic implants are quite satisfactory. Specifically, for dental implants, survival rates range from $90 \%$ to $96.5 \%$ [7-10], whereas for orthopedic implants the same rates are reported as follows: $80-94 \%$ at 15 years for total hip arthroplasty (THA) [11], 98.4-98.7\% at 10 years for total knee prosthesis (TKP) [12], 91\% at 10 years for shoulder arthroplasty [13], and $53 \%$ and $90 \%$ at 5 years for total elbow arthroplasty (TEA) in patients with posttraumatic arthritis or fractures and inflammatory arthritis, respectively [14]. Reasons for failures in all of the above studies are infection, implant fractures, wear of the articulating surfaces, and implant loosening that can be attributed to stress-shielding effect, septic or aseptic inflammation, material fatigue, and excessive activity by the patient and debonding at the tissue-implant interface. Despite the satisfactory results, there is a need for improvement. For instance, between 2005 and 2030 total arthroplasty revision surgeries are estimated to increase at $137 \%$ and $607 \%$ for hip and knee revision surgeries, respectively [15].

Corrosion is a phenomenon closely related to implant failures [16]. The procedure of corrosion begins after its in vivo implantation of a material in the human body and its contact with the extracellular body fluids [17]. The human body is a hostile environment containing water, complex organic compounds, proteins, amino acids, lymph, saliva, plasma, and a variety of ions, such as sodium, chloride, bicarbonate, oxygen, potassium, calcium, magnesium, and chloride. Upon implantation, corrosion is induced by electrochemical interactions between the implant material and the mentioned chemical compounds [17]. As a result, pitting, fretting, galvanic corrosion, and stress corrosion occur, while the following complications are both mechanical and biological.

Mechanical complications include mainly fatigue fracture and they are accelerated by corrosion $[16,17]$. More specifically, concerning dental implants the percentage of fractures of the material is reported between $0.2 \%$ and $1.5 \%$, in followup intervals up to 15 years [18-20]. Similarly, fractures of metallic implant components were reported at $4.2 \%$ in a study that included 142 consecutive cases of cervical fusion, after an average follow-up interval of at least 3 years [21]. Furthermore $2.3 \%$ of 219 distally fixed femoral stems were fractured during a time interval from 1 to 6 years in a prospective study [22]. Lakstein et al. reported that one (1.4\%) out of 69 patients with total hip arthroplasty needed revision after follow-up periods ranging from 5 to 9.5 years [23].

Biological complications related to corrosion are caused by the metal ion release and include toxicity, carcinogenicity, and hypersensitivity [17]. Biocorrosion, tribocorrosion, and their combination result in release of metallic particles from the implant material to peri-implant tissues and other body organs [24-27]. This phenomenon is more intense when biofilms or high concentrations of fluoride are present, a common situation in the oral environment [28]. Specifically, the presence of metallic ions activates macrophages, neutrophils, and T-lymphocytes and provokes enhanced output of cytokines and metallic proteases [29, 30]. Furthermore, in the case of Ti-6Al-4V, aluminum and vanadium particles have been characterized as toxic and mutagenic, respectively, and have been accused for osteomalacia, Alzheimer's disease, and neurological disorders [31-35].

The stress-shielding effect is another phenomenon related to implant failure [36]. In the case of orthopedic implants, the bone is not properly loaded, because of implant rigidity and, consequently, the implant is progressively loosened, due to bone atrophy $[36,37]$. It seems that this situation is inhibited or at least decelerated with the use of more elastic implant alloys [38]. In particular, Young's modulus value for the bone ranges between $6.9 \pm 4.3 \mathrm{GPa}$ and $25.0 \pm 4.3 \mathrm{GPa}$ [39-41], while the same value for cp-Ti and Ti-6Al-4V is $103-107 \mathrm{GPa}$ and 114-120 GPa, respectively [42]. It can be assumed that there is a need for more elastic Ti-alloys to be used as orthopedic implant materials.

As a bioinert material, titanium allows close apposition of bone under proper conditions. This procedure is called osseointegration [43] and begins with the absorption of ions, proteins, polysaccharides, and proteoglycans by the Ti-oxide layer [44, 45]. Afterwards, macrophages, neutrophils, and osteoprogenitor cells migrate on the bone-implant interface and lead to bone apposition in close contact with the implant surface [45]. Although a direct contact between bone and implant can be observed, this situation is not common. More often, there is a thin amorphous zone or lamina limitans [4547], which appears to have a thickness of 20-50 nm [46], or according to other studies it is larger and does not exceed $400 \mathrm{~nm}$ [47]. The osseointegration procedure takes a time period of at least 3-5 months to be adequate [44], a fact that often complicates immediate loading of orthopedic and dental implants.

Consequently, there is a need for new Ti-alloys and surface treatments with the following characteristics:

(i) High corrosion resistance, lower modulus of elasticity, high mechanical strength, and wear resistance to avoid mechanical failures.

(ii) Better biocompatibility, without allergic reactions, cytotoxicity, and carcinogenicity, in order to avoid biological failures.

(iii) More bioactive surfaces that will lead to faster and more enhanced osseointegration.

(iv) Increased antimicrobial properties that will reduce failures due to infection.

\section{New Ti-Alloys}

2.1. Porous Ti-Alloys. Porous surfaces seem to induce bone ingrowth $[48,49]$. Based on that concept, Ti-implants with 
different porosities have been introduced [50-55]. Two types of pores can be detected by SEM observation on a porous $\mathrm{Ti}$ implant surface: (a) macropores $(>100 \mu \mathrm{m})$ that are created by the use of space holders and (b) small micropores $(\sim 10 \mu \mathrm{m})$ that can be observed on the walls of the macropores and arise during the sintering process $[51,55]$. However, the optimal pore size facilitating cell colonization still remains unanswered and findings from different studies are ambiguous and conflicting. Xue et al. conducted MTT assays of porous $\mathrm{cp}-\mathrm{Ti}$ samples ( $27 \%$ porosity, pores size between 100 and $800 \mu \mathrm{m})$ versus nonporous ones on cloned osteoblastic precursor cell lines 1 (OPC1), derived from human fetal bone tissue [51]. Cell numbers were significantly higher on porous Ti-surfaces after 3 days $(p<0.01)$ and 10 days $(p<0.05)$, whereas after 21 days porous surfaces had still more cells but there was no statistically significant difference compared to the nonporous Ti-sample. The same authors demonstrated that cells could not grow into pores that are sized less than $100 \mu \mathrm{m}$, whereas cell bridges were formed between elongations of adjacent cells in pores that are sized $150 \mu \mathrm{m}$. In pores larger than $200 \mu \mathrm{m}$ the cells grew into the center of the pores without forming cell bridges. Furthermore, Hollander et al. tested in vitro the performance of porous Ti-6Al-4V samples fabricated by direct laser forming (DLF) on human primary osteoblast cultures (HOB) [54]. After 14 days, live/dead staining showed complete overgrowth of cells in pores that are sized $500 \mu \mathrm{m}$. On the contrary, pores with sizes $700 \mu \mathrm{m}$ and $1000 \mu \mathrm{m}$ were not completely overgrown but led to circular growth patterns.

Interconnectivity between pores has also been tested as a factor affecting bone ingrowth into porous implants [52]. Otsuki et al. evaluated 3D bone ingrowth on four sintered porous Ti-samples using micro-CT [52]. Ammonium hydrogen was used as a space holder. The samples (50\% porosity, $250-500 \mu \mathrm{m}$ pores size) were implanted into femoral condyles of male rabbits for 6 weeks. The authors concluded that pore throats narrower than $52 \mu \mathrm{m}$ did not allow bone ingrowth. However, they highlighted that different Ti-alloys with different surface treatments may demonstrate different threshold values.

Attempts have been made to describe the relationship between the density and structure of porous materials and their mechanical properties [56-58]. A simplified model to express the relationship between porosity and mechanical properties has been developed [59]:

$$
\begin{aligned}
& \frac{E^{*}}{E_{s}}=C_{1}\left(\frac{\rho^{*}}{\rho_{s}}\right)^{m_{1},}, \\
& \frac{\sigma^{*}}{\sigma_{s}}=C_{2}\left(\frac{\rho^{*}}{\rho_{s}}\right)^{m_{2}},
\end{aligned}
$$

where $E, \sigma$, and $\rho$ correspond to elastic modulus, strength, and density, respectively, while superscript "*" refers to porous materials and the subscript " $s$ " refers to dense materials. $C_{1}$ and $C_{2}$ are dimensionless constants that depend on the type of the material, while $m_{1}$ and $m_{2}$ are exponentials that depend on the type of porosity (open- or closed-cell foams). According to (1) that was proposed by Ashby et al.
TABLE 1

\begin{tabular}{lcc}
\hline Porosity & $64 \%$ & $76 \%$ \\
\hline Young's modulus & $3.3 \pm 0.8 \mathrm{GPa}$ & $2.1 \pm 0.5 \mathrm{GPa}$ \\
\hline Compressive strength & $102 \pm 10 \mathrm{MPa}$ & $23 \pm 10 \mathrm{MPa}$ \\
\hline
\end{tabular}

[59], strength and elastic modulus of porous materials are increased as porosity is decreased.

However, in such theoretical models critical factors such as type of phases, grain size, and microstructure are not taken into consideration [59]. Thus, stress concentration and deformation characteristics are neglected $[60,61]$. On the contrary, finite element models are more reliably used for the simulation of the mechanical behavior of porous implants $[56,62]$. More specifically, Niu et al. developed a two-scale model that describes the mechanical behavior of porous materials and takes into consideration both the macro- and the microporous structure [63].

As aforementioned, porosity affects the mechanical properties of porous implants $[59,64,65]$. According to Jha et al., Young's modulus decreases linearly when density is decreased [66]. Consequently, it is possible to manufacture Ti-implants with elastic modulus comparable to that of human cortical bone $(6.9-25.0 \mathrm{GPa})[39,41]$. Xue et al. fabricated porous implants with $27 \%$ porosity and pore size that ranged between 100 and $800 \mu \mathrm{m}$, using laser engineered net shaping (LENS) method [51]. They found values of elastic modulus and mechanical strength that ranged between 2.6-44 GPa and 24-463 MPa, respectively [51]. Furthermore, Chen et al. fabricated $\mathrm{cp}$-Ti samples with two different porosities $(64 \%$ and $76 \%$ ) using cp-Ti powder and $\mathrm{H}_{2} \mathrm{O}_{2}$ as foaming reagent [55]. The values for compressive strength and modulus of elasticity for the two different porosities were shown in Table 1.

Similarly, in another study, the modulus of elasticity of a Shape Memory Alloy (SMA) was investigated [67]. Rodshaped porous NiTi specimens with different porosities were fabricated via powder metallurgy technique. As the porosity increased from $35.5 \%$ to $42.1 \%$, Young's modulus decreased from $8 \mathrm{GPa}$ to $6 \mathrm{GPa}$ [67].

Pore size has been also investigated as a factor influencing the mechanical properties [68-70]. Tuncer et al. conducted compressive tests on cp-Ti with different porosities between $35 \%$ and $75 \%$ and pores size between $150 \mu \mathrm{m}$ and $1700 \mu \mathrm{m}$ [69]. They found that both the elastic modulus and the compressive strength were increased from $3.8 \mathrm{GPa}$ to $6.1 \mathrm{GPa}$ and from $43 \mathrm{MPa}$ to $87 \mathrm{MPa}$, respectively, when the size of macropores was increased from $150 \mu \mathrm{m}$ to $1700 \mu \mathrm{m}$ [69]. Furthermore, pore randomization (uniform or of different sizes, orientation, and shape of pores) may increase stress concentrations in a microstructural level and provoke early localized plastic deformation [71].

Stress concentrations inside the pores of Ti-implants can be reduced by silanization $(2.0 \%$ of 3 -methacryloxypropyltrimethoxysilane) of the walls of the pores and subsequent filling of the pores with poly-methylmethacrylate (PMMA) [72]. This procedure results in higher tensile strengths (50-250 MPa, depending on the porosity and pore 
size) due to adhesion of the PMMA to the titanium pore walls leading to reduced stress concentrations [72]. Thus, it is possible to manufacture porous Ti-implants with improved tensile strength, while maintaining the elastic modulus in the same low levels (15-60 GPa, depending on the porosity and pore size) [72]. PMMA presents a significantly lower elastic modulus (2-4 GPa) than titanium. Eventually, the Young modulus of the PMMA-Ti complex remains low, despite the increase in tensile strength [72]. However, there are still concerns about the toxicity of the residual methylmethacrylate (MMA) monomer that remains after polymerization $[73,74]$. It can be concluded that porous materials have great advantages, such as a low modulus of elasticity and osteoconductive properties, but there are also some disadvantages. Much progress should be made to improve their mechanical properties, so that they will become suitable biomaterials for load bearing orthopedic and dental implants.

Different methods have been proposed for manufacturing $\mathrm{cp}$-Ti or Ti-alloy porous implants. The fabrication method directly affects the porosity, pore size, orientation and geometry, presence of impurities, and contamination of the biomaterial. Some of the fabrication techniques are as follows:

(i) loose sintering powder [75],

(ii) space holder method [50, 76, 77],

(iii) spark plasma sintering or field assisted consolidation technique $[78,79]$,

(iv) microwave sintering [80],

(v) metal injection molding [81],

(vi) capsule free hot isostatic pressing [82, 83],

(vii) solid state isothermal foaming technique [84],

(viii) freeze casting $[85,86]$ and reverse freeze casting [87],

(ix) combustion synthesis [88],

(x) slip casting [89],

(xi) gel casting [90],

(xii) slurry foaming [91],

(xiii) entangled metallic wire materials [92],

(xiv) rapid prototyping techniques: selective laser melting (SLM) [93], selective electron beam melting (SEBM) [94], and laser engineered net shaping (LENS) [95].

2.2. $\beta$-Phase Ti-Alloys. Titanium is an allotropic element, which means that it exists in more than one crystallographic form [5]. At room temperature, the crystal structure of titanium is hexagonal closed-packed (hcp, $\alpha$-phase), whereas, at $888^{\circ} \mathrm{C}$, this structure transforms to body-centered cubic (bcc, $\beta$-phase) [5]. The transformation temperature (beta transus) is defined as the lowest equilibrium temperature at which the material is $100 \%$ beta and is strongly dependent on [5]

(i) the interstitial elements oxygen, nitrogen, and carbon (alpha stabilizers) which raise the transus temperature; (ii) hydrogen (beta stabilizer), which lowers the transformation temperature;

(iii) metallic impurity or alloying elements which can either raise or lower the transformation temperature.

Alloying elements can be generally classified as alpha or beta stabilizers [5]. Alpha stabilizers, for example, aluminium, oxygen, and nitrogen, favor the $\alpha$-phase of Ti within the alloy by rising the transformation temperature. Beta stabilizers, such as vanadium, tantalum, niobium, molybdenum, nickel, chromium, copper, and iron, result in stability of the beta phase at lower temperatures [5]. Hafnium and zirconium are unique in that they are isomorphous with both the alpha and beta phases. Hence, it is common to classify the Ti-alloys into four categories, referring to the phases that predominate within the alloy [5]:

(i) Alpha.

(ii) Near-alpha.

(iii) Alpha-beta.

(iv) Beta.

In the titanium biomaterials currently used, the crystallographic structure of titanium is alpha phase (cp-Ti) or alphabeta phase (Ti-6Al-4V, Ti-6Al-4Nb) [42].

The $\mathrm{w} / \mathrm{v}$ percentage of the beta stabilizer into the Ti-alloy is crucial in order to obtain the bcc crystallographic structure [5]. In one study, the structure-property relationship of cast $\mathrm{Ti}-\mathrm{Nb}$ alloys was tested [96]. The authors after using X-ray diffraction concluded that alloys containing $15 \% \mathrm{w} / \mathrm{v}$ or less niobium are dominated by hexagonal alpha phases, whereas in alloys with $27.5 \% \mathrm{w} / \mathrm{v}$ niobium metastable beta phase starts to be retained. When niobium contents become $30 \% \mathrm{w} / \mathrm{v}$ or higher the beta phase was almost entirely retained.

Moreover, $\beta$-phase Ti alloys seem to be a very promising material for biomedical applications, due to their low elastic modulus and increased corrosion resistance [97, 98]. The elastic moduli of different $\beta$-phase $\mathrm{Ti}$ alloys are listed in Table 2 . The elastic behavior of Ti-alloys with $\beta$-phase stabilizer strongly depends on the concentrations of the stabilizers inside the alloy [99-101]. Sakaguchi et al. investigated the effect of Ta content on the elastic modulus of a Ti-30Nb$X$ Ta-5Zr alloy $\left(X_{O}=0, X_{1}=5, X_{2}=10, X_{3}=15\right.$, $X_{4}=20$ ) [101]. They reported that for Ta contents below $10 \% \mathrm{w} / \mathrm{v}$ the alloy displays a Stress Induced Martensite (SIM) behavior, while its microstructure consists of $\beta$ - and $\omega$-phases [101]. As the content of Ta increases to $10 \%$ Young's modulus decreases and the alloy becomes more elastic [101]. When the Ta content exceeds $15 \% \mathrm{w} / \mathrm{v}$, the $\beta$-phase predominates within the alloy; thus the elastic modulus increases towards the elastic modulus of pure Ta (181 GPa) [101]. On the contrary, Zhou et al. reported that Young's modulus of the TiXTa alloy shows its maximum decrease $(65 \mathrm{GPa})$ at $X=30 \% \mathrm{w} / \mathrm{v}$, then peaks at $X=50 \% \mathrm{w} / \mathrm{v}(90 \mathrm{GPa})$, and finally decreases again $(65 \mathrm{GPa})$ at $X=70 \% \mathrm{w} / \mathrm{v}$ [100]. Additionally, Correa et al. investigated the effect of $\mathrm{Zr}$ content on Young's modulus of TiXZr alloys $(X=0, X=5, X=10, X=15)$ [102]. The results indicated that the elasticity of the alloy is increased at 
TABLE 2

\begin{tabular}{lcc}
\hline$\beta$-alloys content & $\begin{array}{c}\text { Elastic } \\
\text { modulus } \\
(\mathrm{GPa})\end{array}$ & $\begin{array}{c}\text { Elastic } \\
\text { modulus } \\
\text { after aging } \\
(\mathrm{GPa})\end{array}$ \\
\hline Ti-15Zr [102] & 112 & $\mathrm{NR}$ \\
Ti-15Zr-4Nb-4Ta-0.2Pd-0.2O-0.05N [151] & 100 & 97 \\
Ti-10Zr [102] & 95 & $\mathrm{NR}$ \\
Ti-15Zr-4Nb-4Ta-0.2Pd [151] & 94 & 99 \\
Ti-16Nb-13Ta-4Mo [97] & 91 & 113 \\
Ti-15Sn-4Nb-2Ta-0.2Pd [151] & 89 & 103 \\
Ti-5Zr [102] & 87 & $\mathrm{NR}$ \\
Ti-15Sn-4Nb-2Ta-0.2Pd-0.2O [151] & 86 & 98 \\
Ti-15Zr-10Cr [99] & 80 & NR \\
Ti-29Nb-13Ta [97] & 76 & 103 \\
Ti-15Mo [102] & 75 & NR \\
Ti-13Nb-13Zr [102] & 75 & NR \\
Ti-29Nb-13Ta-4Mo [97] & 74 & 73 \\
Ti-29Nb-13Ta-6Sn [97] & 74 & 73 \\
Ti-29Nb-13Ta-2Sn [97] & 62 & 78 \\
Ti-19Zr-10Nb-1Fe [98] & 59 & $\mathrm{NR}$ \\
Ti-29Nb-13Ta-7Zr [102] & 53 & $\mathrm{NR}$ \\
Ti-10Zr-5Nb-5Ta (ARB processed) [104] & 43 & $\mathrm{NR}$ \\
\hline
\end{tabular}

a $\mathrm{Zr}$ content of $5 \% \mathrm{w} / \mathrm{v}$, whereas higher concentrations of $\mathrm{Zr}$ lead to an increase of the elastic modulus of the alloy [102].

The corrosion resistance of $\beta$-phase $\mathrm{Ti}$ alloys has also been investigated extensively. Ribeiro et al. conducted electrochemical impedance spectroscopy (EIS) tests to assess the corrosion behavior of $\mathrm{Ti}-35 \mathrm{Nb}-5 \mathrm{Zr}$ and $\mathrm{Ti}-35 \mathrm{Nb}-10 \mathrm{Zr}$, using Ti-6Al-4V as control [103]. The mean passive current densities $\left(i_{\text {pass }}\right)$ of the 2 alloys $\left(i_{\text {pass }(\mathrm{Ti}-35 \mathrm{Nb}-5 \mathrm{Zr})}=6.28 \pm\right.$ $0.34 \mu \mathrm{A} / \mathrm{cm}^{2}$ and $\left.i_{\text {pass }(\mathrm{Ti}-35 \mathrm{Nb}-10 \mathrm{Zr})}=11.90 \pm 4.11 \mu \mathrm{A} / \mathrm{cm}^{2}\right)$ were comparable $(p>0.05)$ with this of Ti-6Al-4V $\left(i_{\text {pass }}(\mathrm{Ti}-6 \mathrm{Al}-4 \mathrm{~V})\right.$ $\left.=7.29 \pm 0.85 \mu \mathrm{A} / \mathrm{cm}^{2}\right)$. The mean corrosion potentials $\left(E_{(i=0)}\right)$ between the three alloys $\left(E_{(i=0) \mathrm{Ti}-35 \mathrm{Nb}-5 \mathrm{Zr}}=0.276 \pm 0.058 \mathrm{~V}\right.$, $E_{(i=0) \mathrm{Ti}-35 \mathrm{Nb}-10 \mathrm{Zr}}=0.349 \pm 0.060 \mathrm{~V}, E_{(i=0) \mathrm{Ti}-6 \mathrm{Al}-4 \mathrm{~V}}=0.286 \pm$ $0.015 \mathrm{~V})$ were not statistically significant $(p>0.05)[103]$.

However, the manufacturing processes appear to be very important to the corrosion resistance of the material [104, 105]. Raducanu et al. compared the corrosion resistance between an as-cast Ti-10Zr-5Nb-5Ta alloy and an Accumulative Role Bonding (ARB) processed Ti-10Zr-5Nb-5Ta alloy in Ringer's solution $\left(\mathrm{pH}=6.9,37^{\circ} \mathrm{C}\right)$ [104]. After cyclic potentiodynamic polarization, they concluded that the ARB-processed alloy exhibits better corrosion resistance $\left(i=0.142 \mu \mathrm{A} / \mathrm{cm}^{2}, E_{\text {corr }}=0.450 \mathrm{~V}\right)$ than the as-cast $\left(i=0.230 \mu \mathrm{A} / \mathrm{cm}^{2}, E_{\text {corr }}=0.450 \mathrm{~V}\right)[104]$. Furthermore, Gill et al. investigated the corrosion behavior of Ti-30Ta manufactured by two different fabrication methods, powder metallurgy (PM) and ARC-melting (ARC) [105]. The cyclic potentiodynamic corrosion curve of the ARC manufactured Ti-30Ta exhibited a clockwise loop with hysteresis, related to less corrosion resistance when compared to PD [105].
Among the beta stabilizers reported, niobium, zirconium, and tantalum present favorable biocompatibility results. In one study, niobium and zirconium exhibited excellent biocompatibility, while tantalum exhibited medium biocompatibility when tested in cell cultures of murine calvaria osteoblast-like cells (MC3T3-E1) [42]. In another study, TI$25 \mathrm{Nb}$ alloy samples with different percentages of porosity were inserted for $3 \mathrm{~h}, 24 \mathrm{~h}$, and $72 \mathrm{~h}$, in a rabbit bone marrow mesenchymal stem cell (BMMSC) incubator, at $37^{\circ} \mathrm{C}, 5 \%$ $\mathrm{CO}_{2}$, and $100 \%$ relative humidity [106]. After fluorescent microscopy and SEM observations it was concluded that $\mathrm{Ti}$ $25 \mathrm{Nb}$ alloys show good biocompatibility regardless of the percentage porosity. Similarly, in another in vitro study, De Andrade et al. assessed different parameters of osteogenesis of dense and porous $\mathrm{cp}$-Ti and $\mathrm{Ti}-35 \mathrm{Nb}$ samples in rat calvariaderived cells [107]. The findings indicated that cell numbers were higher in the cp-Ti sample at 3 days of cultivation $(p<0.05)$ [107]. However, at 7 days, cell numbers were not statistically significant between the two materials [107]. MTT assay revealed that cell viability was not affected by the type of the material, whereas, after 14 days, dense Ti$35 \mathrm{Nb}$ samples exhibited the highest alkaline phosphatase activity (ALP) $(p<0.05)$ [107]. In addition, in an in vivo study, Ti-50Zr alloy samples were tested after 8 months of implantation inside spleens of female F344/DuCrj rats. After hematological and histological analyses, it was outlined that the alloy presents better biocompatibility than cp-Ti [108]. Sista et al. compared in vitro the biological behavior of $\mathrm{Ti}$ $50 \mathrm{Nb}, \mathrm{Ti}-50 \mathrm{Zr}$, and $\mathrm{cp}$-Ti using mouse osteoblast cell cultures (MC3T3-E1) [109]. After the first 4 hours of plating there were statistically significant differences $(p<0.05)$ between cell adhesion on $\mathrm{Ti}-50 \mathrm{Zr}(35 \%)$ and $\mathrm{cp}-\mathrm{Ti}(27 \%)$ and $\mathrm{Ti}-50 \mathrm{Nb}$ (27\%) [109]. However, regarding the spreading of cells there were similar findings on all surfaces at 8 hours of plating [109]. Data from cell viability suggests that after 24 hours the survival of cells on the $\mathrm{Ti}-50 \mathrm{Zr}$ surface was $70 \%$, while the respective value for $\mathrm{cp}-\mathrm{Ti}$ and $\mathrm{Ti}-50 \mathrm{Nb}$ was $50 \%(p<0.05)$ [109]. Cell numbers were $17.5 \times 10^{3}$ for the Ti-50Zr and $17 \times$ $10^{3}$ for $\mathrm{cp}$-Ti, which were significantly $(p<0.05)$ higher than those of Ti-50Nb $\left(11 \times 10^{3}\right)$ [109]. Similarly, ALP activity at 7 days was significantly higher $(p<0.05)$ for cp-Ti and Ti-50Zr $(\sim 0.155$ (IU/L)/ug protein) than for Ti-50Nb $(0.07$ (IU/L)/ug protein) [109].

2.3. Titanium Bulk Glasses. Metals and metal alloys are characterized by a microcrystalline structure. On the contrary, bulk metallic glasses (BMGs) are metallic materials with noncrystalline structure [110]. The first BMG was produced by Klement et al. in 1960 from an $\mathrm{Au}_{75} \mathrm{Si}_{25}$ alloy [111]. Since then, BMGs have been widely investigated, due to their excellent mechanical properties, such as superior strength, high corrosion fatigue, wear resistance, and low modulus of elasticity $[112,113]$.

Inoue expressed three empirical rules to describe the glass forming ability (GFA) of the BMGs [114, 115]. Firstly, the glasslike structure of these materials is a result of solidification with an extremely high cooling rate that does not allow for the formation of the typical crystal nucleation of the alloy [110]. 
Furthermore, in order to achieve high glass forming ability (GFA) the alloy system should be comprised of three or more alloying elements and, thirdly, their atomic size ratios should exceed $10 \%$ [110].

Over the last 25 years many Ti-based BMGs have been fabricated based on Ti-Ni-Cu [116-121], Ti-Zr-Be [122124], and Ti-Zr-Cu-Ni [125-128]. However, those Ti-based BMGs cannot be used for biomedical applications because of the cytotoxicity of Ni- [129] and Be- elements [130]. This fact has led to the development of ternary $\mathrm{Ti}-\mathrm{Zr}-\mathrm{Cu}-\mathrm{Pd}$ with $\mathrm{Pd}$ instead of $\mathrm{Ni}$ - and $\mathrm{Be}-[131,132]$. Among them, $\mathrm{Ti}_{40} \mathrm{Zr}_{10} \mathrm{Cu}_{36} \mathrm{Pd}_{14}$, with compressive strength of $1950 \mathrm{MPa}$ and Young's modulus of $82 \mathrm{GPa}$, presents the higher glass forming ability $[131,133]$.

$\mathrm{Zhu}$ et al. reported that substituting $\mathrm{Cu}$ by $\mathrm{Sn}$ at $2 \%$ in Ti-Zr-Cu-Pd BMGs improves the GFA of the alloy [134]. Furthermore, $\mathrm{Ti}-\mathrm{Zr}-\mathrm{Cu}-\mathrm{Pd} \mathrm{BMG}$ with minor additions of $2 \% \mathrm{Sn}$ present a compressive strength of $2000 \mathrm{MPa}$ [135]. Oak et al. investigated the mechanical behavior of $\mathrm{Ti}_{45} \mathrm{Zr}_{10} \mathrm{Pd}_{10} \mathrm{Cu}_{31} \mathrm{Sn}_{4}$ BMG and reported a compressive strength of about $1970 \mathrm{MPa}$, Vickers's hardness of $650 \mathrm{Hv}$, and Young's modulus of $95 \mathrm{GPa}$ [136]. Moreover, this BMG alloy presents a crystallization temperature of $681 \mathrm{~K}$ and a glass formation temperature of $737 \mathrm{~K}$ [136]. Consequently, it displays a wide supercooled liquid region $\left(\Delta T_{X}\right)$ of $56 \mathrm{~K}$, which may allow its shaping when heated [136]. Additionally, Qin et al. tested the corrosion rate of $\mathrm{Ti}_{45} \mathrm{Zr}_{10} \mathrm{Pd}_{10} \mathrm{Cu}_{31} \mathrm{Sn}_{4} \mathrm{BMG}$, in terms of weight loss after immersion in a $1 \mathrm{~N} \mathrm{HCl}$ solution (room temperature $\approx 298 \mathrm{~K}$ ) [137]. It was reported that the corrosion rate of this Ti-based BMG was $0.046 \mathrm{~mm}$ year $^{-1}$, much lower than that of stainless steel $0.28 \mathrm{~mm}_{\text {year }}{ }^{-1}$ [137].

Furthermore, Pang et al. performed minor additions of $2 \% \mathrm{Ag}$, an element with antimicrobial effect and enhanced GFA [138]. They developed a $\mathrm{Ti}_{47} \mathrm{Cu}_{38} \mathrm{Zr}_{7.5} \mathrm{Fe}_{2.5} \mathrm{Sn}_{2} \mathrm{Si}_{1} \mathrm{Ag}_{2}$ BMG with compressive strength, specific strength, Young's modulus, and Vickers' microhardness of $2080 \mathrm{MPa}, 3.2 \times$ $105 \mathrm{~N} \mathrm{~m} / \mathrm{kg}, 100 \mathrm{GPa}$, and $588 \mathrm{Hv}$, respectively [138]. Its glass transition temperature $\left(T_{G}=641 \mathrm{~K}\right)$ and crystallization temperature $\left(T_{X}=693 \mathrm{~K}\right)$ allow for a wide supercooled liquid region $\left(\Delta T_{X}\right)$ of $52 \mathrm{~K}$ [138]. Similarly, Wang et al. investigated the effect of different $\mathrm{Ag}$ additions in the $\mathrm{Ti}_{46} \mathrm{Cu}_{31.5-x} \mathrm{Zr}_{11.5} \mathrm{Co}_{3} \mathrm{Si}_{1} \mathrm{Ag}_{x}(x=0,1,2,3,4,5$ at\%) [139]. They indicated that when $x=4 \%$ the structure is fully glassy and does not present any crystalline phase. They concluded that the GFA is enhanced by the addition of Ag because the difference between the melting temperature and the crystallization temperature is increased [139].

Other elements that were investigated for minor addition into Ti-based BMGs are $\mathrm{Si}$ [140], $\mathrm{Nb}$ [141], and noble elements, such as Au and Pt [142]. According to Qin et al., the addition of $1 \%$ of noble alloys led to the development of a $\mathrm{Ti}_{40} \mathrm{Zr}_{10} \mathrm{Cu}_{36} \mathrm{Pd}_{14} \mathrm{M}_{x}$ BMG with high yield strength (2000 MPa), low Young's modulus, and improved plastic strain (1.5-10\%) [142]. Furthermore, the addition of $1 \% \mathrm{Si}$ enhanced the GFA of $\mathrm{Ti}_{40} \mathrm{Zr}_{10} \mathrm{Cu}_{36} \mathrm{Pd}_{14}$, due to the increase of its $\Delta T_{X}(60 \mathrm{~K})[140]$. A very promising element for addition to $\mathrm{Ti}-\mathrm{Zr}-\mathrm{Cu}-\mathrm{Pd} \mathrm{BMG}$ appears to be $\mathrm{Nb}$ [141]. In a study conducted by Qin et al., different contents of $\mathrm{Nb}$ in Ti-Zr-Cu-Pd
BMGs were investigated [141]. It was concluded that the addition of $3 \% \mathrm{Nb}$ leads to the development of a BMG with superior mechanical properties (yield strength: $2050 \mathrm{MPa}$, Young's modulus: $80 \mathrm{GPa}$, and plastic strain: 6.5\%). Moreover, according to Fornell et al., the addition of $3 \% \mathrm{Nb}$ in the $\mathrm{Ti}-\mathrm{Zr}-\mathrm{Cu}-\mathrm{Pd} \mathrm{BMGs}$ results in superior corrosion resistance (corrosion density: $3.77 \times 10^{-6} \mathrm{~A} / \mathrm{cm}^{2}$, corrosion potential: $0.007 \mathrm{~V}$, and pitting potential: $0.412 \mathrm{~V}$ ) [143].

Recently, Wang et al. develop another Ti-Cu-Hf-Si BMG, based on a binary-eutectic rule that allows the prediction of GFA in relation to the composition [144]. The rule is based on (2) to predict the composition Cam of the BMG [145]:

$$
\begin{aligned}
\mathrm{Cam}= & \alpha\left(\mathrm{Ti}_{57} \mathrm{Cu}_{42}\right)+\beta\left(\mathrm{Cu}_{56.4} \mathrm{Hf}_{43.6}\right) \\
& +\gamma\left(\mathrm{Ti}_{86.5} \mathrm{Si}_{13.5}\right), \\
\alpha \Delta H_{(\mathrm{TiCu})}= & \beta \Delta H_{(\mathrm{CuHf})}=\gamma \Delta H_{(\mathrm{TiSi})},
\end{aligned}
$$

where $\alpha, \beta$, and $\gamma$ are coefficients for the three main units and $\Delta H_{(\mathrm{TiCu})}, \Delta H_{(\mathrm{CuHf})}$, and $\Delta H_{(\mathrm{TiSi})}$ are the mixing heats of the clusters, $-9 \mathrm{~kJ} / \mathrm{mol},-17 \mathrm{~kJ} / \mathrm{mol}$, and $-66 \mathrm{~kJ} / \mathrm{mol}$, respectively [145]. From (2) arises the fact that $\alpha=0.6, \beta=0.318$, and $\gamma=0.082$. So the Cam becomes $\mathrm{Ti}_{41.3} \mathrm{Cu}_{43.7} \mathrm{Hf}_{13.9} \mathrm{Si}_{1.1}$ [144]. This BMG exhibits ultimate strength of $1685 \mathrm{MPa}$, Young's modulus of $95 \mathrm{GPa}$, and supercooled region $\left(\Delta T_{X}\right)$ of $40^{\circ} \mathrm{C}$ [144]. Furthermore, its corrosion potentials in $\mathrm{NaCl}$ and Hank's solution are $-0.164 \mathrm{~V}$ and $-0.624 \mathrm{~V}$, respectively, indicating a good corrosion resistance comparable with that of Ti-6Al-4V [144].

Concerning the biocompatibility of Ti-based BMGs, Oak et al. tested the cytotoxicity of $\mathrm{Ti}_{45} \mathrm{Zr}_{10} \mathrm{Cu}_{10} \mathrm{Pd}_{31} \mathrm{Sn}_{4}$ in vitro, using osteoblast cell cultures (SaOS2) in $36.85^{\circ} \mathrm{C}$ for 8 days [146]. They reported that the content of $\mathrm{Cu}$ in the BMG was not enough to cause cytotoxicity, due to the biochemical corrosion after immersion to Phosphate Buffered Solution (PBS) and $1 \%$ lactic acid solution [146]. Similarly, Pang et al. investigated the cytotoxicity of the $\mathrm{Ti}_{47} \mathrm{Cu}_{38} \mathrm{Zr}_{7.5} \mathrm{Fe}_{2.5} \mathrm{Sn}_{2} \mathrm{Si}_{1} \mathrm{Ag}_{2}$ BMG using cultures of the MC3T3-E1 cell-line for 3 days [138]. The Ti-6Al-4V alloy was used as a control. They reported that the biocompatibility of the BMG is comparable with that of a Ti-6Al-4V alloy. SEM observations on the surface of the $\mathrm{Ti}_{47} \mathrm{Cu}_{38} \mathrm{Zr}_{7.5} \mathrm{Fe}_{2.5} \mathrm{Sn}_{2} \mathrm{Si}_{1} \mathrm{Ag}_{2}$ BMG revealed overlapped layers of cells, connected with cytoplasmic elongations, while on the surface of the Ti-6Al-4V samples there was one layer of polygonal cells [138]. Wang et al. performed direct and indirect cytotoxicity tests in order to investigate the biocompatibility of $\mathrm{Ti}_{41.5} \mathrm{Zr}_{2.5} \mathrm{Hf}_{5} \mathrm{Cu}_{37.5} \mathrm{Ni}_{7.5} \mathrm{Si}_{1} \mathrm{Sn}_{5}$ BMG (TZHCNSS) [147]. They used murine fibroblast cultures (1929 cells and NIH3T3 cells) and cp-Ti as control. However, the results indicated proliferation rates of $60 \%$ for 1929 cells and 55-65\% for NIH3T3 cells at 4 days [147]. Despite this low cell viability in vitro, which was attributed to $\mathrm{Cu}$ content, the in vivo results were more promising [147]. After 1 month of implantation in the mandibles of 6 dogs, light microscopy (100x magnification) observations revealed good osteointegration. The difference between in vitro and in vivo tests was attributed to the fact that in a living organism the metabolism does not allow for the accumulation of $\mathrm{Cu}$ ions [147]. 
Moreover, not all surface treatments are feasible on BMGs, because only low temperature processes can be performed without compromising the mechanical properties of these materials [148-150]. Qin et al. investigated the ability of rod-shaped $\mathrm{Ti}_{40} \mathrm{Zr}_{10} \mathrm{Cu}_{36} \mathrm{Pd}_{14} \mathrm{BMG}$ to form an apatite layer after acidic $\left(5 \% \mathrm{HCl}+30 \% \mathrm{HNO}_{3}\right.$ for $10 \mathrm{~s}$ at room temperature), alkali, and heat treatment $\left(5 \mathrm{M} \mathrm{NaCl}\right.$ at $60^{\circ} \mathrm{C}$ for $24 \mathrm{~h}$ ) and immersion in simulated body fluids (SBF) [148]. They highlighted that despite the fact that the BMG became porous there was no apatite layer formation [148]. For this reason, they created a pure-titanium layer, using Ti sputtering technique before the alkali and heat treatments. After X-ray energy dispersive spectroscopy (EDS), a sodium titanate layer was observed on the surface of the BMG. Following 15 days of immersion in SBF a CaP apatite layer of $300 \mathrm{~nm}$ thickness was developed on the surface of the Ti-treated $\mathrm{Ti}_{40} \mathrm{Zr}_{10} \mathrm{Cu}_{36} \mathrm{Pd}_{14}$ BMG [148]. The apatite formation mechanism is further explained in the following chapter for surface treatments. However, the bonding strength between the Ti-coating and the BMG should be further investigated [148]. Additionally, the apatite formation ability of a $\mathrm{Ti}_{42} \mathrm{Hf}_{11} \mathrm{Pd}_{11} \mathrm{Cu}_{36} \mathrm{BMG}$ was induced after anodic oxidation by potentiostatic polarization at $25^{\circ} \mathrm{C}$ in a $1 \mathrm{M} \mathrm{NaOH}$ solution [150]. In another study two other coatings of $\mathrm{TiN}$ and $(\mathrm{Ti}, \mathrm{Al}) \mathrm{N}$ on $\mathrm{Ti}_{40} \mathrm{Zr}_{10} \mathrm{Cu}_{36} \mathrm{Pd}_{14}$ BMG were developed by magnetron sputtering (PVD) [149]. The porosities of the $\mathrm{Ti}_{40} \mathrm{Zr}_{10} \mathrm{Cu}_{36} \mathrm{Pd}_{14}$ BMG with the two different coatings are $6.4 \%$ and $2.7 \%$ for $\mathrm{TiN}$ - and $(\mathrm{Ti}, \mathrm{Al}) \mathrm{N}-$, respectively [149]. The corrosion passive current density was $8.8 \times 10^{-4} \mathrm{~A} / \mathrm{m}^{2}$ and $8.4 \times 10^{-4} \mathrm{~A} / \mathrm{m}^{2}$ for TiN- and $(\mathrm{Ti}, \mathrm{Al}) \mathrm{N}$ coatings, respectively, when calculated by polarization curves in Hank's solution [149]. Those values are much lower than that of the BMG substrate $\left(3.5 \times 10^{-3} \mathrm{~A} / \mathrm{m}^{2}\right)$, showing that these coatings probably decrease the overall passive current density of the material, increasing its corrosion resistance [149]. The corrosion resistance is further enhanced because of the increase of the corrosion potential at $0.02 \mathrm{~V}$ for the TiN-coated BMG and at $0.05 \mathrm{~V}$ for the (Ti, Al)N-coated BMG [149].

\section{New Surface Treatment Modifications}

\subsection{Surface Modifications to Improve the Mechanical Proper- ties of the Implant}

3.1.1. Anodic Oxidation. Anodic oxidation is an accelerated electrochemical oxidation process based on electrode reactions and leading to the formation of an oxide film on the anode metal surface [152]. Titanium is coated by an oxide surface layer of $1.5-10 \mathrm{~nm}$ thickness that is formed naturally on the titanium surface on the exposure to air at room temperature [153]. Consequently, anodic oxidation of titanium surface results in the production of a thicker oxide film than that formed spontaneously at the metal surface. It should be mentioned that the oxide film has very important role in the implant's biocompatibility since it is this surface rather than the main body of the titanium implant that comes in direct contact with the bone tissue [154]. Based on this fact, many surface modifications have been investigated so as to enhance the properties of this thin oxide layer [155].
Among the various techniques, the anodic oxidation is a well-established and promising method, since it can produce different types of oxide films on titanium surfaces. The thickening of the oxide film obtained by the anodic oxidation may contribute to the increase of the corrosion and wear resistance, as well as to the improvement of the adhesion and bonding [152].

The properties of the formed oxide layer depend on the process parameters, such as the anode voltage and the electrolyte composition. Regarding the applied voltage, high voltages produce thick and porous oxide films, while low voltages produce thin and compact films [154]. As for the electrolyte, different acids such as $\mathrm{H}_{2} \mathrm{SO}_{4}, \mathrm{H}_{3} \mathrm{PO}_{4}$, and acetic acid, neutral salts, and alkaline solutions can be used for the titanium anodization $[156,157]$. It has been reported that the alkaline electrolytes such as calcium hydroxide and sodium hydroxide revealed a relatively lower ability of anodic oxide formation than the acidic ones [156].

The titanium oxide layer shows three different crystalline forms: anatase (tetragonal), rutile (tetragonal), and brookite (orthorhombic). It has been reported that the anatase and rutile structures of the titanium oxide layer have the ability to form hydroxyapatite, a bioactive material that can induce bioactive bonding with the surrounding bone enhancing the osseointegration [158-160]. Yang et al. have demonstrated that the anodic oxidation in $\mathrm{H}_{2} \mathrm{SO}_{4}$ solution combined with heat treatment at $600^{\circ} \mathrm{C}$ for $1 \mathrm{~h}$ led to the apatite formation due to the increasing of the anatase and rutile structures in the titanium oxide layer [159]. It has been revealed that the anodic oxidation treatment led to the increase of the corrosion resistance of titanium implants [161]. Leinenbach and Eifler investigated the influence of the oxidation treatment on the fatigue behavior of the titanium and found that the oxide film obtained by the anodic oxidation could withstand higher stress amplitudes (325 Mpa) and higher plastic strains (before the first surface damage) than the oxide films produced by thermal oxidation $(275 \mathrm{MPa})$.

3.1.2. Chemical Vapor Deposition (CVD). Chemical vapor deposition is a process resulting in the deposition of a solid material on a substrate's surface from the chemical reaction between gaseous precursors and the heated surface of the metal substrate $[162,163]$. A gas delivery system supplies the reactor chamber of the CVD apparatus with chemical gases which come into contact with a heated substrate in order to react and decompose forming a solid phase that coats the substrate. The heating of the substrate may be accomplished by tube furnaces, halogen lamps, induction heating lasers, or UV light. Furthermore, the gaseous precursors can be halides, hydrides, and various metal compounds such as carbonyls and alkoxides. During this process, chemical by-products are produced that are removed from the reactor chamber along with the unreacted precursor gases via an exhaust and a vacuum system $[152,163]$. Various types of the CVD processes have been used such as the atmospheric pressure CVD, the low pressure CVD, the metal-organic CVD, the plasmaassisted CVD, the laser CVD, the photochemical CVD, the chemical vapour infiltration, and the chemical beam epitaxy [163]. 
Among the various applications of the CVD [162], the formation of a solid coating on the metal surface resistant to the corrosion and wear is an attractive method for the preparation of implants surface intended for a highly corrosive environment like that of the human body [164]. It has been demonstrated that the CVP process of titanium implants results in the enhancement of the wear and corrosion resistance of these materials. Furthermore, many authors found that the diamond-like-carbon (DLC, an amorphous form of carbon) coating produced by various CVD methods on the titanium surfaces has enhanced mechanical properties, such as wear and corrosion resistance along with a good biocompatibility [165-168]. However, it should be mentioned that the thermal expansion of the diamond film is highly different from the thermal expansion of the titanium leading to a poor film adhesion on the titanium substrate [152]. It has been demonstrated that this drawback can be overcome by the use of an intermediate layer in order to improve the adhesion of the DLC coating $[165,169,170]$. Specifically, Kim et al. prepared DLC-coated Ti alloys with the incorporation of an amorphous silicon intermediate layer using the plasmaassisted CVD technique and found an improvement in the corrosion resistance in a simulated corrosive environment of the body fluid by a $0.89 \% \mathrm{NaCl}$ solution [166]. This finding is in agreement with the result of another study, which demonstrated that the wear resistance of a $1 \mu \mathrm{m}$ thick DLC layer was statistically significant higher than that of the noncoated titanium surfaces [165]. Moreover, the anticorrosion nature of the silicon layer incorporated to titanium surfaces has been also supported by other studies $[167,171]$. Lastly, except from the DLC coating, the formation of titanium carbide layer on titanium surface by an ion-enhanced triode plasma CVD led to high abrasion resistance encouraging the use of this layer as abrasion resistant implant material [172].

\subsection{Surface Modifications to Induce Bioactivity, Cell Growth, and Osseointegration}

3.2.1. Sandblasting/Grit-Blasting, Acid-Etching: Formation of Porous Surface. The surface characteristics of the implants affect the behavior of the surrounding bone and consequently the implant's osseointegration process. Various studies have reported that the implants with rough surfaces demonstrated better behavior and higher survival rates compared with the machined ones [173-175]. Specifically, Pinholt found that the survival rate of rough implants was $98 \%$, while that of machined implants was $81 \%$, in a follow-up period of 20 to 27 months [174]. Furthermore, Gotfredsen et al. revealed that implants blasted with titanium-dioxide-particles showed a better anchorage and bone-implant contact than the machined implants [175]. The superiority of rough implants over the machined ones regarding bone formation is based on the surface microtopography modification and the alteration of the surface energy which leads to proteins and blood components absorption enhancing the cell attachment and implant osseointegration [176].

Based on this finding, various surface modifications have been tried to produce micro-rough titanium surfaces, including sandblasting, acid-etching, and surface chemistry alterations, in order to enhance the osseointegration process of these implants. The blasting process is based on abrasive particles (i.e., alumina, corundum, rutile, and hydroxyapatite) forced against the implant's surface. Regarding the acid-etching process of titanium surfaces, $\mathrm{HCl}, \mathrm{H}_{2} \mathrm{SO}_{4}$, and $\mathrm{HF}$ are used as acids, since they are able to react with the oxide layer formed on the titanium surface [177]. As for the surface chemistry, ionic interactions, protein absorption, and cellular activity at the implant surface are altered, resulting in modifications of biologic events such as the osseointegration [178].

Specifically, Abdel-Haq et al. found that the chemically modified sand-blasted acid-etched implants achieved a higher bone-to-implant contact compared with the standard sand-blasted acid-etched implants in the early weeks of healing, while no statistically significant difference was found in the bone contact between the 2 types of implants after 6 weeks of healing [179]. It should be mentioned that the surface chemical alteration by nitrogen rinsing and storage in a $\mathrm{NaCl}$ solution results in increased wettability and hydrophilicity of the titanium surface [179-181]. Various studies have reported that the hydrophilic nature of implants which were modified by sand-blasting and acid-etching improved their osseointegration when compared with unmodified rough implants [180-183]. Similarly, Patel et al. supported the significance of the wettability and hydrophilicity of micro-rough implants in the cellular attachment and subsequently in their effective osseointegration. They mentioned that the hydrophilicity of the micro-rough titanium implants increased after each one of the following treatment procedures: (a) deionized water rinse followed by nitrogen drying, (b) sonication in methanol, (c) deposition of a $10 \mathrm{~nm}$ thick $\mathrm{TiO}_{2}$ film, and finally (d) water wash and nitrogen drying of the rough titanium samples covered with the $\mathrm{TiO}_{2}$ layer [184]. Also, the same authors stated that the high hydrophilicity is attributed to the removal of the inorganic and organic surface contaminants by the cleaning treatment. Finally, a prospective study by Karabuda et al. demonstrated that the marginal bone loss difference was statistically significant between the standard and modified sand-blasted, acid-etched implants after 15 months of evaluation, while the difference of the survival rates between the 2 types of implants was not statistically significant [185].

3.2.2. Alkaline Treatment: Coating CaP. An alkali-treated Tisurface is negatively charged [186]. Consequently, in acellular simulated biofluids (SBF), it tends to absorb the positively charged calcium ions $[186,187]$. As the accumulation of calcium progresses, the surface becomes more positively charged, leading to phosphate ion absorption and thereafter apatite formation [186, 187]. This procedure was experimentally confirmed by X-ray photoelectron spectroscopy for different time intervals $[188,189]$.

Furthermore, for the apatite layer formation, heat treatment after alkali solution exposure is essential. More specifically, when a Ti-surface is exposed to an alkali solution (i.e., $\mathrm{NaOH}$ ) sodium hydrogen titanate is formed [190]. By heat treatment, sodium hydrogen titanate transforms to sodium 
titanate $\left(\mathrm{Na}_{2} \mathrm{Ti}_{3} \mathrm{O}_{7}\right)$, which exchanges $\mathrm{Na}^{+}$ions for $\mathrm{H}_{3} \mathrm{O}^{+}$in SBF [190].

In an in vivo study, Yan et al. exposed Ti-rectangular specimens to alkaline solution of $5 \mathrm{M} \mathrm{NaOH}$ at $60^{\circ} \mathrm{C}$ for $24 \mathrm{~h}$ and then heat treated them at $600^{\circ} \mathrm{C}$ for 1 hour [191]. Afterwards the specimens were inserted into 8 tibias of 4 rabbits. Eight weeks after implantation, the surrounding woven and lamellar newly formed bone was observed in direct contact with an apatite layer on the surface of the specimens. Similarly, in another animal study, a Ti-metal rod was exposed in $5 \mathrm{M} \mathrm{NaOH}$ solution at $60^{\circ} \mathrm{C}$ for $24 \mathrm{~h}$ and heat treated to $600^{\circ} \mathrm{C}$ for $1 \mathrm{~h}$. Four weeks after implantation into a rabbit femoral condyle, bone islands were present even in the deepest part of the pores on the surface of the specimen [192]. Tsukanaka et al. investigated the proliferation and differentiation of osteoblasts around alkali and heat treated cp-Ti culture plates-in $5 \mathrm{M} \mathrm{NaOH}$ solution at $60^{\circ} \mathrm{C}$ for $24 \mathrm{~h}$ and heat treated to $600^{\circ} \mathrm{C}$ for $1 \mathrm{~h}$-versus nontreated cp-Ti plates, using fluorescent primary osteoblasts [193]. It was reported that the onset of differentiation on the surface treated plates was accelerated. However, once the procedure had started no important differences between the two groups were identified. Nevertheless, SEM observations have disclosed that the osteoblasts on the surface treated plates were small and round, whereas the osteoblasts on the nontreated surface group were larger and flat [193].

Concerning Ti-alloys, alkali and heat treatments have been attempted in Ti-6Al-4V [194-196], Ti-6Al-2Nb-Ta [194, 196], and Ti-15Mo-5Zr-3Al alloys [194, 196]. Apatite formation in SBF and bone bonding were achieved on the surfaces in all above mentioned alloys and are attributed to specific alloying elements (i.e., $\mathrm{Al}, \mathrm{V}$, and $\mathrm{Mo}$ ), whereas, in other Ti-alloys, which contain $\mathrm{Ta}, \mathrm{Zr}$, and $\mathrm{Nb}$, like TNZT alloys (Ti-Nb-Zr-Ta), the sodium release is inhibited and apatite formation is suppressed $[194,196]$. Another disadvantage of the alkali-heat-treated titanium surfaces is that the apatite formation is sensitive to even small amount of Ca ions [197].

The above problems have resulted in the replacement of sodium titanate with calcium titanate [198-200]. After the exposure in a $\mathrm{NaOH}$ solution, the Ti-alloy was soaked in a $100 \mathrm{Mm} \mathrm{CaCl}_{2}$ solution at $40^{\circ} \mathrm{C}$ for $24 \mathrm{~h}$. This step allows the $\mathrm{Na}^{+}$ions to be replaced by $\mathrm{Ca}^{2+}$ ions and, subsequently, the sodium titanate to be replaced by calcium titanate. In SBF, the $\mathrm{Ca}^{2+}$ ions are replaced via exchange with $\mathrm{H}_{3} \mathrm{O}^{+}$ions, resulting in the formation of $\mathrm{TiOH}$ on the Ti-metal surface. This procedure progressively makes the surface more negatively charged and combines with the positively charged $\mathrm{Ca}^{2+}$ ions that had been released. Then, negatively charged phosphate ions are attracted by the $\mathrm{Ca}^{2+}$ ions, resulting in a crystalline apatite [198]. This treatment has allowed apatite formation on new Ti-alloys such as Ti-15Zr-4Nb-4Ta [199, 201], Ti-29Nb13Zr-4.6Ta [201], and Ti-35Nb-2Ta-3Zr-0.3O [200, 202].

Concerning clinical applications of alkaline and heat treatments, a total of 70 hip arthroplasties were performed in 58 patients (mean age 51.7 years), using orthopedic implants made of Ti-6Al-2Nb-1Ta alkaline and heat treated [203]. In a mean 10-year follow-up the overall survival rate was $98 \%$ (CI 95\%) [204]. Two implants were retrieved after failing due to deep infection and periprosthetic femoral fracture-at 2 weeks and 8 years after implantation-and underwent histologic examination, which revealed newly grown bone, even on the implant, which was retrieved as early as 2 weeks after implantation [204]. Additionally, 5 spinal fusion devices, made of alkaline and heat treated $\mathrm{cp}$-Ti, were applied to 5 patients with a very successful outcome and a rapid recovery [205]. Future applications of apatite layer include the utilization of these layers as carriers for drugs [206], such as bisphosphonates, growth factors [207], and DNA [208].

3.2.3. Acid Treatment: Coating CaP. Furthermore, acid treatment leads to a positively charged titanium surface that has an affinity to absorb negatively charged phosphate ions in SBF. Afterwards, the accumulation of phosphate ions, which makes the titanium surface progressively more negatively charged, provokes the absorption of calcium ions. This procedure gradually leads to apatite formation on the titanium surface, as was confirmed by X-ray photoelectron spectroscopy [186, 209].

It seems that heat treatment after exposure to acidic solution enhances bone formation [210, 211]. In one animal study, two Ti-metal specimens that had been exposed to a strong acidic solution $\left(66.3 \% \mathrm{w} / \mathrm{w} \mathrm{H}_{2} \mathrm{SO}_{4}\right.$ solution and $10.6 \% \mathrm{w} / \mathrm{w} \mathrm{HCl}$ solution in a $1: 1$ weight ratio) for $1 \mathrm{~h}$ and heat treated at $600^{\circ} \mathrm{C}$ for another $1 \mathrm{~h}$ were implanted into rabbit tibias [210]. Four weeks after, newly formed bone with parallel collagen fibers in direct contact with one specimen was observed and, eight weeks after, bone remodeling had occurred on the surface of the second specimen. On the contrary, in specimens that had been exposed to pure water instead of acidic solution prior to heat treatment or had not been heat treated at all, fibrous tissue encapsulation was observed [210]. These findings are in agreement with another in vivo study, where Ti-specimens were exposed to the same acidic solution $\left(\mathrm{H}_{2} \mathrm{SO}_{4} / \mathrm{HCl}\right)$ for $30 \mathrm{~min}$ and heat treated at $600^{\circ} \mathrm{C}$ for $1 \mathrm{~h}$ [211]. The specimens were inserted into a dorsal muscle of a beagle dog and after 12 months newly formed ectopic bone was observed on its porous and charged surface (zeta potential: $8.0( \pm 2.0) \mathrm{mV})$. On the contrary, in the same study, specimens that had not been heat treated after acidic exposure or that had been exposed to pure water prior to heat treatment showed no bone formation within 12 months, almost zero surface charge (zeta potential: $\sim 0 \mathrm{mV}$ and -2.1 $( \pm 3.1) \mathrm{mV}$, resp.), and no surface apatite formation after being embedded to SBF [211].

Things become more complicated when it comes to Tialloys [209]. Alloying elements form other oxides-apart from Ti-oxides-on the alloy surface, limiting the capacity of apatite formation in SBF. However, in the case of Ti-15Zr$4 \mathrm{Nb}-4 \mathrm{Ta}$, exposure to $\mathrm{NaOH}$ solution, prior to $\mathrm{HCl}$ solution and heat treatment, resulted in a positively charged titanium oxide layer and apatite formation in SBF [212].

Furthermore, findings from the above studies indicate that titanium exposure to acidic solution and following heat treatment has not only osteoconductive but also osteoinductive properties, due to the apatite layer formation in its surface. 
3.2.4. Biochemical Modification. Biochemical modification aims at utilization of cell adhesion and differentiation properties in order to achieve faster osseointegration and bone adhesion. Surface immobilization of extracellular matrix (ECM) proteins and their effects in bone stimulation have been investigated thoroughly. More specifically, attempts have been made in order to immobilize proteins $[213,214]$, peptides [215], and growth factors on implant surfaces [216].

Among ECM proteins, collagen I is a very promising candidate for protein immobilization [217]. The procedure includes amino groups deposition from allylamine plasma, placement in a $0.1 \%$ collagen type I solution at $37^{\circ} \mathrm{C}$ overnight, to initiate fibrillogenesis, and covalent linking obtained by carbodiimide (EDC) and N-hydroxysuccinimide in an aqueous solution [218]. Morra et al. have evaluated the regenerative properties of collagen I coatings, in vitro, both on osteoblast-like cell (SaOS2) cultures [218] and on human mesenchymal cell (HMC) cultures [219]. In the first study, collagen coated titanium (ColTi) and noncoated titanium (Ti) had no significant differences, concerning the growth of SaOS2 cells [218]. On the contrary, in the case of HMC, ColTi stimulated cell adhesion and density in short experimental time and the surface details were completely followed by the cell bodies [219]. The above findings suggest that osteoblastlike cells' adhesion is controlled by surface topography, whereas HMC are chemically stimulated [218, 219]. In the above-mentioned studies, covalent immobilization was used; however absorptive immobilization of collagen I has also been described [213]. In this case, the titanium samples were soaked in a $0.1 \%$ collagen type I solution for $6 \mathrm{~h}$, water cleaned ultrasonically, and finally dried under vacuum [213]. Ao et al. evaluated absorptive and covalent immobilization of collagen type I on Ti-6Al-4V samples, concerning adhesion, proliferation, and differentiation of HMC [213]. Their findings suggest that covalent immobilization is superior to absorptive, regarding both the amount and stability of collagen type I [213].

Furthermore, in vivo studies have also showed successful outcomes [218, 220-222]. Morra et al. investigated bone to implant contact of 8 ColTi implants and 8 noncoated $\mathrm{Ti}$ implants, in the cortical bone of femur and the trabecular bone of tibia of eight adult rabbits [218]. Two weeks after implantation, bone to implant contact was sufficiently higher in ColTi implants than in the noncoated Ti implants. Additionally, Sverzut et al. implanted 12 titanium implants, surface treated with covalently immobilization of collagen type I, in the mandibles of 6 mongrel dogs [221]. Another group of 12 nontreated titanium implants was also implanted to be used as control. The animals were euthanized 3 and 8 weeks after implantation and histomorphometric, cellular, and molecular analyses were performed. Histomorphometric analyses showed no signs of inflammation or fibrous tissue formation adjacent to the implants, while surface treatment clearly affected bone to implant contact $(p<0.001)$. Cellular analysis showed no difference in the number of osteoblastic cells, but there were higher levels of alkaline phosphatase adjacent to ColTi implants. Molecular analysis indicated that RNA that was extracted from bone adjacent to ColTi implants showed higher expression of genes that encode alkaline phosphatase, runt-related transcription factor 2, osteocalcin, and bone sialoprotein [221]. In another study, Korn et al. inserted 36 screw-type cp-Ti implants in the mandibles of 6 female Berlin minipigs [220]. Of the 36 implants, 12 were noncoated, 12 were surface treated resulting in a chondroitin sulfate-containing collagen coating, and the rest of 12 were surface treated resulting in a sulfated hyaluronan-containing collagen coating. After 4- and 8-week healing periods, histologic evaluation indicated higher bone maturation in the coated implants. After the 4-week healing period chondroitin sulfate-containing collagen coated implants had statistically significant superior spongious bone to implant contact (spongious BIC) compared to sulfated hyaluronan-containing collagen coated implants $(p<0.05)$, whereas after 8 weeks of healing this difference was not statistically significant [220]. Last but not least, Sartori et al. compared ColTi coated implants versus noncoated $\mathrm{Ti}$ implants in 20 healthy and 20 osteopenic rats [222]. The implants were made of $\mathrm{cp}$-Ti and received a hydrofluoric acidetching treatment. The collagen was covalently immobilized onto implant surfaces. The implants were implanted into the femoral condyles of the rats and left for a healing period that ranged from 4 to 12 weeks. Each rat received a ColTi implant in the right condyle and a Ti implant in the left condyle. Histomorphometric investigation showed that the total bone to implant contact was significantly higher in the ColTi implants, compared to Ti implants in both the healthy and osteopenic rat models [222].

Lately, short biomimetic peptides have been immobilized on implant surfaces [215, 223]. Short peptides are used because they are cheaper and they can be more easily obtained in high purity, larger quantity, and better stability [215]. The mostly used peptides are tripeptide Arg-GlyAsp (RGD) motifs that are derived from fibronectin and vitronectin, which play a pivotal role in cell adhesion [215]. Dettin et al. used two peptides for surface functionalization, (GRGDSP) ${ }_{4} \mathrm{~K}$ which contains tripeptide RGD and (352360) HPV, and investigated the properties of promoting cell adhesion of osteoblast-like cells [215]. The (313-324) HIV$\mathrm{I}_{\mathrm{MN}}$ gp120 peptide was used as a control. The peptides were covalently immobilized onto the surfaces of $\mathrm{cp}$-Ti (grade 2) disks. Adhesion assays were conducted on Sprague-Dawley rat osteoblasts cells. The findings indicated that both peptides result in an increase of osteoblast adhesion whereas (352360) HPV leads to higher bone density [215].

Growth factors have also been immobilized onto implant surfaces to obtain a biomimetic implant behavior [216]. Seol et al. investigated a synthetic peptide which mimics BMP2. The peptide was immobilized onto titanium disk surfaces via a cross-linker SMCC. The procedure included APTES grafting, an activation of the implant surface via a 2\% hexane solution (stirred for $30 \mathrm{~min}$ under argon bubbling). Then, the disks underwent reaction with SMCC and finally they were washed and grafted with the peptide in a $2 \mathrm{mg} / 0.5 \mathrm{~mL}$ phosphate buffered saline [216]. The disks were tested both in vitro, in osteoblast-like MC3T3-E1 cells, and in vivo, after implantation into the mandibles of two beagle dogs. The growth rate of the MC3T3-E1 cells in the case of the surface treated disks was significantly higher 
than in the untreated ones, which were used as a control [216]. Furthermore, using fluorescently labeled phalloidin, adherent microfilament bundles of actin were observed to the surface of the peptide Ti-disks, whereas no evidence of such attachment was noticed on Ti-disks. Regarding the implants that were retrieved from the mandibles of the dogs, the histological analysis showed higher bone maturation in the peptide Ti-disks with thicker trabeculae, indicating a faster bone maturation [216].

\subsection{Surface Modifications with Antibacterial Effects}

3.3.1. Antibiotic and Nonantibiotic Organic Coatings. Antibiotics with broad antibacterial spectra, such as gentamicin, cephalothin, carbenicillin, amoxicillin, cefamandole, metronidazole, simvastatin, tobramycin, and vancomycin, have been incorporated in coatings of bone implants. Calcium phosphate and carbonated hydroxyapatite have been used in in vitro studies as carriers of vancomycin and tobramycin to minimize the initial bacterial adhesion [224226]. These studies have shown that both calcium phosphate and carbonated hydroxyapatite loaded with antibiotics and used as coatings effectively inhibited the growth of Staphylococcus aureus [224-226]. Moreover, in an in vitro study, Liu et al. integrated simvastatin and metronidazole into a calcium phosphate coating for titanium surface and found that this bifunctional coating prevented the growth of the Porphyromonas gingivalis [227].

In addition to these coatings, biodegradable polymers and so-gel films have been proposed as controlled-release antibiotic-laden coatings on titanium surfaces. Specifically, Gollwitzer et al. prepared a biodegradable poly(D,L-lactic acid) coating with integrated gentamicin and teicoplanin on titanium surfaces and found a statistically significant reduction in the bacterial adhesion of Staphylococcus epidermidis when compared to the uncoated titanium alloys [228]. In other studies biodegradable poly(lactic-co-glycolic acid) coatings containing antibiotics were prepared by an electrospinning technique. The electrospinning process is based on the nanotechnology and produces polymeric nanofibers which can be used as drug delivery agents. These studies demonstrated that the antibiotic-loaded electrospun coating on titanium implants significantly reduced the adhesion of Staphylococcus aureus compared with the bare titanium implants in vitro and in vivo [229, 230]. However, the increase of microbial organisms resistant to antibiotics remains a considerable issue in the application of the drugs clinically. Moreover, some drug-containing coatings continue to release antibiotics at low concentrations for longer periods of time increasing the risk of antibiotic resistance. Finally, there are in vitro studies recording that some antibiotics provoke cell toxicity. Specifically, Ince et al. mentioned that the decreased osteoblastic activity may be attributed to the inhibition of protein synthesis provoked by the gentamycin at concentration greater than $100 \mu \mathrm{g} / \mathrm{mL}$ [231]. Furthermore, Antoci et al. demonstrated a reduction in the osteoblast proliferation after the cells exposure to ciprofloxacin, tobramycin, and vancomycin even at the lowest dose of $25 \mu \mathrm{g} / \mathrm{mL}$ for the ciprofloxacin. However, further in vitro and in vivo studies are required to assess the exact effect of the antibiotics on the human cells [231-233].

With the increase of microbial organisms resistant to several antibiotics, the application of nonantibiotic organic antimicrobial agents, such as chlorhexidine and chloroxylenol, has been investigated. Titanium surface has the capacity to absorb chlorhexidine and release it gradually over a long period of time [234, 235]. However, several studies have shown that the nonantibiotic organic antimicrobial agents can adversely affect human osteoblasts. Specifically, it was speculated that the chlorhexidine provoked lysis of the fibroblasts membrane leading to the cellular death. However, further investigation should be conducted in order for definitive conclusions to be drawn regarding the biocompatibility of the nonantibiotic antimicrobial agents [231,236].

An alternative approach to the prevention of the bacteria adhesion is the modification of implants' surface characteristics. In vitro studies have shown that ultraviolet light irradiation (UV) treatment of Ti-6Al-4V prevents bacteria colonization [237, 238]. Moreover, some bioactive polymers, such as chitosan and hyaluronic acid, bonded to titanium demonstrated improved osteoblast attachment and inhibition of bacterial attachment [239, 240]. However, the in vivo performance of these molecules is not known.

3.3.2. Inorganic Antimicrobial Coatings. One of the most promising and attractive approaches of obtaining antibacterial coatings for titanium is the incorporation of inorganic metallic antimicrobial agents on the titanium oxide layer [241-244]. Silver is a white, brilliant, and ductile metallic element with atomic number 47 in the periodic table. Pure silver has the highest electrical and thermal conductivity of all metals and possesses the lowest contact resistance [245]. The antimicrobial effect of silver (Ag) has been recognized since antiquity [246]. Other medical applications of Ag as coating for prevention of biofilm formation include the incorporation into bandages for cutaneous wounds, vascular, urinary and peritoneal catheters, prosthetic heart valve rings, vascular grafts, and sutures [247, 248].

Nanotechnology includes fields of science and technology and is based on the development of materials with dimensions in nanoscale level. Nanotechnology has a large range of applications such as in medicine, electronics, and biomaterials energy production. Nanoparticles are atoms between 1 and 100 nanometers in size, with enhanced chemical and mechanical properties. Among different types of nanomaterials, silver nanoparticles are considered to be the most antimicrobial against bacteria and viruses, due to their large surface area to volume ratio [249].

Regarding the antibacterial mechanism of Ag, the exact interaction between silver nanoparticles and bacteria is not known and thus there are many references proposing several possible mechanisms. It is believed that $\mathrm{Ag}$ binds to bacterial deoxyribonucleic acid (DNA), dissociating the hydrogen bonds between purine and pyrimidine bases and hence preventing the replication of DNA and cell division [250]. Another possible mechanism is the binding of silver to bacterial cell proteins and enzymes, such as the sulfhydryl groups leading to denaturation, disruption of the 
cell metabolism, and finally death [251, 252]. It has been reported that the extracellular binding of positively charged Ag nanoparticles to negatively charged peptidoglycans on bacteria walls is essential for the antimicrobial activity of Ag causing structural changes and cell atrophy [250]. Lastly, Slawson et al. believe that the antimicrobial mechanism of silver lays in the release of Ag ions into the cell, achieved by a transport system for molecules of similar charge and size [252].

Previous studies suggest that Ag nanoparticles, incorporated as a coating to titanium surfaces, are effective growth inhibitors of Staphylococcus aureus and Escherichia coli, preventing their adhesion or proliferation to these surfaces [243, 244]. Moreover, Jin et al. [253] investigated the antibacterial effect of zinc $(\mathrm{Zn})$ and silver $(\mathrm{Ag})$ coimplantation into titanium plates against $S$. aureus and $E$. coli both in vitro and in vivo and found a reduction in the bacterial growth on the $\mathrm{Zn} / \mathrm{Ag}$ coimplanted titanium [253]. Another study examined the antibacterial activity of a biomimetic coating enriched by calcium (Ca), phosphorous (P), silicon ( $\mathrm{Si})$, and silver (Ag) nanoparticles and incorporated into the titanium surfaces. This study demonstrated a significant reduction in survivability of Streptococcus mutans, Streptococcus epidermidis, and Escherichia coli [254]. It should be mentioned however that the above examined strains are not representative of oral bacteria found in peri-implant disease [255]. Although there is no evidence for the presence of a limited number of specific bacteria in the peri-implantitis, in general, the microbiota associated with peri-implant disease is similar to the subgingival flora of chronic periodontitis and consists of Porphyromonas gingivalis, Prevotella intermedia, Tannerella forsythia, Fusobacterium sp., Actinomycetes, S. mutans, V. parvula, S. sanguinis, and S. gordonii [255]. Nevertheless, the antimicrobial activity of Ag nanoparticles incorporated to titanium surfaces against these peri-implant bacteria has not been investigated thoroughly in the literature. Massa et al. examined the antibacterial effect of a silica-based composite coating containing Ag nanoparticles on the titanium surface against the Aggregatibacter actinomycetemcomitans, although Mombelli and Décaillet found that this microorganism is less frequently in the peri-implant diseases than the aforementioned bacteria [255, 256].

Besides the silver, other inorganic antimicrobial agents such as zinc $(\mathrm{Zn})$, copper $(\mathrm{Cu})$, and fluorine $(\mathrm{F})$ have also been used as antibacterial coatings to titanium implants. However, silver is the most preferable, due to its broad antibacterial spectrum to both Gram-positive and Gramnegative bacteria, its long-lasting antibacterial effect, its biocompatibility, and its stability [257]. Previous studies have examined the antimicrobial effect of zinc [258, 259]. However, the reduction of the bacteria growth achieved by the zinc was not long-lasting [260]. Li et al. prepared coatings containing titanium ( $\mathrm{Ti}$ ) nanotubes and zinc $(\mathrm{Zn})$ on titanium foils and found prevention on the bacterial colonization for 2 weeks [261]. However, it was found that this antibacterial action decreased with time. Moreover, there is evidence that the incorporation of copper $(\mathrm{Cu})$ into the titanium alloys increases their antimicrobial effect. It should be mentioned however that copper ion implantation compromises the mechanical properties of the metals reducing their corrosion and wear resistance $[262,263]$.

\section{Conclusion}

Titanium and its alloys are a very promising biomaterial for the fabrication of medical and dental implants, due to the excellent mechanical properties and biocompatibility. The introduction of $\beta$-phase stabilizers and bulk metallic glasses in the Ti-alloys has enabled the development of new alloys with high mechanical strength and low modulus of elasticity that allows proper loading of the bone. Furthermore, the high corrosion resistance and biocompatibility of these new alloys will limit failures such as fatigue fractures, implant loosening, and adverse reactions due to ion release. Additionally, porous surfaces and bioactive implant coatings seem to improve the bioactivity of implants and lead to faster and more enhanced osseointegration. Moreover, surface coatings with antimicrobial effects are very promising for limiting failures due to infection.

Although much progress has been made it seems that there are still many improvements to be achieved. Fabrication methods and their parameters appear to play a pivotal role on the mechanical properties, corrosion resistance, pore size, and distribution of the materials. Furthermore, cellular interactions with the modified implant surfaces have to be fully understood at a nanometer level, in order to manufacture implants with high osseointegration rates and strong antibacterial effects. The findings of the current literature are very promising, but there is still room for improvement for implants that will provide a better quality of life to both medical and dental patients.

\section{Conflict of Interests}

The authors declare that there is no conflict of interests regarding the publication of this paper.

\section{References}

[1] G. Lütjering and J. C. Williams, Titanium, Springer Science \& Business Media, 2013, https://books.google.com/books?id= wBXsCAAAQBAJ\&pgis=1.

[2] M. Long and H. J. Rack, "Titanium alloys in total joint replacement-a materials science perspective," Biomaterials, vol. 19, no. 18, pp. 1621-1639, 1998.

[3] R. L. Sakaguchi and J. M. Powers, Craig's Restorative Dental Materials, Elsevier, Mosby, 13th edition, 2012.

[4] C. Elias, J. Lima, R. Valiev, and M. Meyers, "Biomedical applications of titanium and its alloys," JOM, vol. 60, no. 3, pp. 46-49, 2008.

[5] M. J. Donachie, A Technical Guide: Titanium, American Technical Publishers, 2000.

[6] B. G. Keselowsky, D. M. Collard, and A. J. García, "Surface chemistry modulates fibronectin conformation and directs integrin binding and specificity to control cell adhesion," Journal of Biomedical Materials Research Part A, vol. 66, no. 2, pp. 247-259, 2003. 
[7] I. Naert, M. Quirynen, D. van Steenberghe, and P. Darius, "A sixyear prosthodontic study of 509 consecutively inserted implants for the treatment of partial edentulism," The Journal of Prosthetic Dentistry, vol. 67, no. 2, pp. 236-245, 1992.

[8] T. Jemt and J. Johansson, "Implant treatment in the edentulous maxillae: a 15-year follow-up study on 76 consecutive patients provided with fixed prostheses," Clinical Implant Dentistry and Related Research, vol. 8, no. 2, pp. 61-69, 2006.

[9] R. Adell, B. Eriksson, U. Lekholm, P. I. Brånemark, and T. Jemt, "Long-term follow-up study of osseointegrated implants in the treatment of totally edentulous jaws," The International Journal of Oral \& Maxillofacial Implants, vol. 5, no. 4, pp. 347-359, 1990.

[10] W. Becker, P. Hujoel, B. E. Becker, and P. Wohrle, "Dental implants in an aged population: evaluation of periodontal health, bone loss, implant survival, and quality of life," Clinical Implant Dentistry and Related Research, vol. 17, pp. 461-468, 2015.

[11] K. T. Mäkelä, A. Eskelinen, P. Pulkkinen, P. Paavolainen, and V. Remes, "Total hip arthroplasty for primary osteoarthritis in patients fifty-five years of age or older. An analysis of the finnish arthroplasty registry," The Journal of Bone and Joint SurgeryAmerican Volume, vol. 90, no. 10, pp. 2160-2170, 2008.

[12] P. M. Faris, M. A. Ritter, K. E. Davis, and H. M. Priscu, “Ten-year outcome comparison of the anatomical graduated component and vanguard total knee arthroplasty systems," The Journal of Arthroplasty, vol. 30, no. 10, pp. 1733-1735, 2015.

[13] J. Guery, L. Favard, F. Sirveaux, D. Oudet, D. Mole, and G. Walch, "Reverse total shoulder arthroplasty. Survivorship analysis of eighty replacements followed for five to ten years," The Journal of Bone and Joint Surgery-American Volume, vol. 88, no. 8, pp. 1742-1747, 2006.

[14] M. J. Kraay, M. P. Figgie, A. E. Inglis, S. W. Wolfe, and C. S. Ranawat, "Primary semiconstrained total elbow arthroplasty: survival analysis of 113 consecutive cases," The Journal of Bone \& Joint Surgery-British Volume, vol. 76, no. 4, pp. 636-640, 1994.

[15] S. Kurtz, K. Ong, E. Lau, F. Mowat, and M. Halpern, "Projections of primary and revision hip and knee arthroplasty in the United States from 2005 to 2030," The Journal of Bone and Joint Surgery-American Volume, vol. 89, no. 4, pp. 780-785, 2007.

[16] B. Aksakal, Ö. S. Yildirim, and H. Gul, "Metallurgical failure analysis of various implant materials used in orthopedic applications," Journal of Failure Analysis and Prevention, vol. 4, no. 3, pp. 17-23, 2004.

[17] D. C. Hansen, "Metal corrosion in the human body: the ultimate bio-corrosion scenario," Interface, vol. 17, pp. 31-34, 2008.

[18] S. E. Eckert, S. J. Meraw, E. Cal, and R. K. Ow, "Analysis of incidence and associated factors with fractured implants: a retrospective study," International Journal of Oral and Maxillofacial Implants, vol. 15, no. 5, pp. 662-667, 2000.

[19] E. Romeo and S. Storelli, "Systematic review of the survival rate and the biological, technical, and aesthetic complications of fixed dental prostheses with cantilevers on implants reported in longitudinal studies with a mean of 5 years follow-up," Clinical Oral Implants Research, vol. 23, no. 6, pp. 39-49, 2012.

[20] T. Berglundh, L. Persson, and B. Klinge, "A systematic review of the incidence of biological and technical complications in implant dentistry reported in prospective longitudinal studies of at least 5 years," Journal of Clinical Periodontology, vol. 29, supplement 3, pp. 197-233, 2002.

[21] T. Okamoto, M. Neo, S. Fujibayashi, H. Ito, M. Takemoto, and T. Nakamura, "Mechanical implant failure in posterior cervical spine fusion," European Spine Journal, vol. 21, no. 2, pp. 328-334, 2012.

[22] C. A. Busch, M. N. Charles, C. M. Haydon et al., "Fractures of distally-fixed femoral stems after revision arthroplasty," The Journal of Bone \& Joint Surgery - British Volume, vol. 87, no. 10, pp. 1333-1336, 2005.

[23] D. Lakstein, D. Backstein, O. Safir, Y. Kosashvili, and A. E. Gross, "Revision total hip arthroplasty with a porous-coated modular stem : 5 to 10 years followup," Clinical Orthopaedics and Related Research, vol. 468, no. 5, pp. 1310-1315, 2010.

[24] S. B. Goodman, M. Lind, Y. Song, and R. L. Smith, "In vitro, in vivo, and tissue retrieval studies on particulate debris," Clinical Orthopaedics and Related Research, vol. 352, pp. 25-34, 1998.

[25] M. H. Huo, E. A. Salvati, J. R. Lieberman, F. Betts, and M. Bansal, "Metallic debris in femoral endosteolysis in failed cemented total hip arthroplasties," Clinical Orthopaedics and Related Research, no. 276, pp. 157-168, 1992.

[26] J. C. Wang, W. D. Yu, H. S. Sandhu, F. Betts, S. Bhuta, and R. B. Delamarter, "Metal debris from titanium spinal implants," Spine, vol. 24, no. 9, pp. 899-903, 1999.

[27] W. W. Brien, E. A. Salvati, F. Betts et al., "Metal levels in cemented total hip arthroplasty: a comparison of well-fixed and loose implants," Clinical Orthopaedics \& Related Research, no. 276, pp. 66-74, 1992.

[28] J. C. Souza, M. Henriques, R. Oliveira, W. Teughels, J.-P. Celis, and L. A. Rocha, "Do oral biofilms influence the wear and corrosion behavior of titanium?" Biofouling, vol. 26, no. 4, pp. 471-478, 2010.

[29] R. Kumazawa, F. Watari, N. Takashi, Y. Tanimura, M. Uo, and Y. Totsuka, "Effects of Ti ions and particles on neutrophil function and morphology," Biomaterials, vol. 23, no. 17, pp. 3757-3764, 2002.

[30] D. R. Haynes, S. D. Rogers, S. Hay, M. J. Pearcy, and D. W. Howie, "The differences in toxicity and release of bone-resorbing mediators induced by titanium and cobalt-chromium-alloy wear particles," The Journal of Bone \& Joint Surgery-American Volume, vol. 75, pp. 825-834, 1993.

[31] G. M. Keegan, I. D. Learmonth, and C. P. Case, "Orthopaedic metals and their potential toxicity in the arthroplasty patient: a review of current knowledge and future strategies," The Journal of Bone \& Joint Surgery - British Volume, vol. 89, no. 5, pp. 567573, 2007.

[32] J. J. Rodríguez-Mercado, E. Roldán-Reyes, and M. AltamiranoLozano, "Genotoxic effects of vanadium(IV) in human peripheral blood cells," Toxicology Letters, vol. 144, no. 3, pp. 359-369, 2003.

[33] A. Léonard and R. Lauwerys, "Mutagenicity, carcinogenicity and teratogenicity of cobalt metal and cobalt compounds," Mutation Research, vol. 239, no. 1, pp. 17-27, 1990.

[34] J. L. Domingo, "Reproductive and developmental toxicity of aluminum: a review," Neurotoxicology and Teratology, vol. 17, no. 4, pp. 515-521, 1995.

[35] S. Catalani, S. Stea, A. Beraudi et al., "Vanadium release in whole blood, serum and urine of patients implanted with a titanium alloy hip prosthesis," Clinical Toxicology, vol. 51, no. 7, pp. 550556, 2013.

[36] R. Huiskes, H. Weinans, H. J. Grootenboer, M. Dalstra, B. Fudala, and T. J. Slooff, "Adaptive bone-remodeling theory applied to prosthetic-design analysis," Journal of Biomechanics, vol. 20, no. 11-12, pp. 1135-1150, 1987. 
[37] H. M. Frost, "Skeletal structural adaptations to mechanical usage (SATMU): 2. Redefining Wolff's law: the remodeling problem," Anatomical Record, vol. 226, no. 4, pp. 414-422, 1990.

[38] N. Sumitomo, K. Noritake, T. Hattori et al., "Experiment study on fracture fixation with low rigidity titanium alloy: plate fixation of tibia fracture model in rabbit," Journal of Materials Science: Materials in Medicine, vol. 19, no. 4, pp. 1581-1586, 2008.

[39] T. Gross, D. H. Pahr, F. Peyrin, and P. K. Zysset, "Mineral heterogeneity has a minor influence on the apparent elastic properties of human cancellous bone: a SR $\mu$ CT-based finite element study," Computer Methods in Biomechanics and Biomedical Engineering, vol. 15, no. 11, pp. 1137-1144, 2012.

[40] X. J. Wang, X. B. Chen, P. D. Hodgson, and C. E. Wen, "Elastic modulus and hardness of cortical and trabecular bovine bone measured by nanoindentation," Transactions of Nonferrous Metals Society of China (English Edition), vol. 16, supplement 2, pp. s744-s748, 2006.

[41] M. Cuppone, B. B. Seedhom, E. Berry, and A. E. Ostell, “The longitudinal Young's modulus of cortical bone in the midshaft of human femur and its correlation with CT scanning data," Calcified Tissue International, vol. 74, no. 3, pp. 302-309, 2004.

[42] E. Eisenbarth, D. Velten, M. Müller, R. Thull, and J. Breme, "Biocompatibility of $\beta$-stabilizing elements of titanium alloys," Biomaterials, vol. 25, no. 26, pp. 5705-5713, 2004.

[43] "The glossary of prosthodontic terms," Journal of Prosthetic Dentistry, vol. 94, no. 1, pp. 10-92, 2005.

[44] T. Albrektsson, P.-I. Brånemark, H.-A. Hansson et al., "The interface zone of inorganic implants In vivo: titanium implants in bone," Annals of Biomedical Engineering, vol. 11, no. 1, pp. 1-27, 1983.

[45] D. A. Puleo and A. Nanci, "Understanding and controlling the bone-implant interface," Biomaterials, vol. 20, no. 23-24, pp. 2311-2321, 1999.

[46] K. Murai, F. Takeshita, Y. Ayukawa, T. Kiyoshima, T. Suetsugu, and T. Tanaka, "Light and electron microscopic studies of bone-titanium interface in the tibiae of young and mature rats," Journal of Biomedical Materials Research, vol. 30, no. 4, pp. 523-533, 1996.

[47] P. Thomsen, C. Larsson, L. E. Ericson, L. Sennerby, J. Lausmaa, and B. Kasemo, "Structure of the interface between rabbit cortical bone and implants of gold, zirconium and titanium," Journal of Materials Science: Materials in Medicine, vol. 8, no. 11, pp. 653-665, 1997.

[48] Y. Li, C. Yang, H. Zhao, S. Qu, X. Li, and Y. Li, "New developments of ti-based alloys for biomedical applications," Materials, vol. 7, no. 3, pp. 1709-1800, 2014.

[49] V. Karageorgiou and D. Kaplan, "Porosity of 3D biomaterial scaffolds and osteogenesis,” Biomaterials, vol. 26, no. 27, pp. 5474-5491, 2005.

[50] C. E. Wen, M. Mabuchi, Y. Yamada, K. Shimojima, Y. Chino, and T. Asahina, "Processing of biocompatible porous $\mathrm{Ti}$ and $\mathrm{Mg}$," Scripta Materialia, vol. 45, no. 10, pp. 1147-1153, 2001.

[51] W. Xue, B. V. Krishna, A. Bandyopadhyay, and S. Bose, "Processing and biocompatibility evaluation of laser processed porous titanium," Acta Biomaterialia, vol. 3, no. 6, pp. 1007-1018, 2007.

[52] B. Otsuki, M. Takemoto, S. Fujibayashi, M. Neo, T. Kokubo, and T. Nakamura, "Pore throat size and connectivity determine bone and tissue ingrowth into porous implants: threedimensional micro-CT based structural analyses of porous bioactive titanium implants," Biomaterials, vol. 27, no. 35 , pp. 5892-5900, 2006.
[53] J. P. Li, P. Habibovic, M. van den Doel et al., "Bone ingrowth in porous titanium implants produced by $3 \mathrm{D}$ fiber deposition," Biomaterials, vol. 28, no. 18, pp. 2810-2820, 2007.

[54] D. A. Hollander, M. Von Walter, T. Wirtz et al., "Structural, mechanical and in vitro characterization of individually structured Ti-6Al-4V produced by direct laser forming," Biomaterials, vol. 27, no. 7, pp. 955-963, 2006.

[55] Y. J. Chen, B. Feng, Y. P. Zhu, J. Weng, J. X. Wang, and X. Lu, "Fabrication of porous titanium implants with biomechanical compatibility," Materials Letters, vol. 63, no. 30, pp. 2659-2661, 2009.

[56] A. P. Roberts and E. J. Garboczi, "Elastic properties of model random three-dimensional open-cell solids," Journal of the Mechanics and Physics of Solids, vol. 50, no. 1, pp. 33-55, 2002.

[57] C. M. Ford and L. J. Gibson, "Uniaxial strength asymmetry in cellular materials: an analytical model," International Journal of Mechanical Sciences, vol. 40, no. 6, pp. 521-531, 1998.

[58] A.-F. Bastawros, H. Bart-Smith, and A. G. Evans, "Experimental analysis of deformation mechanisms in a closed-cell aluminum alloy foam," Journal of the Mechanics and Physics of Solids, vol. 48, no. 2, pp. 301-322, 2000.

[59] M. F. Ashby, A. G. Evans, N. A. Fleck, L. J. Gibson, J. W. Hutchinson, and H. N. G. Wadley, Metal Foams: A Design Guide, vol. 54 of Library, 2000.

[60] S. Malinov, Z. Guo, W. Sha, and A. Wilson, "Differential scanning calorimetry study and computer modeling of $\beta \Rightarrow \alpha$ phase transformation in a Ti-6Al-4V alloy," Metallurgical and Materials Transactions A, vol. 32, no. 4, pp. 879-887, 2001.

[61] C. Zou, E. Zhang, M. Li, and S. Zeng, "Preparation, microstructure and mechanical properties of porous titanium sintered by Ti fibres," Journal of Materials Science: Materials in Medicine, vol. 19, no. 1, pp. 401-405, 2008.

[62] A. P. Roberts and E. J. Garboczi, "Elastic moduli of model random three-dimensional closed-cell cellular solids," Acta Materialia, vol. 49, no. 2, pp. 189-197, 2001.

[63] W. Niu, S. Gill, H. Dong, and C. Bai, "A two-scale model for predicting elastic properties of porous titanium formed with space-holders," Computational Materials Science, vol. 50, no. 1, pp. 172-178, 2010.

[64] S. J. Hollister, R. D. Maddox, and J. M. Taboas, "Optimal design and fabrication of scaffolds to mimic tissue properties and satisfy biological constraints," Biomaterials, vol. 23, no. 20, pp. 4095-4103, 2002.

[65] Z. Fang, B. Starly, and W. Sun, "Computer-aided characterization for effective mechanical properties of porous tissue scaffolds," CAD-Computer Aided Design, vol. 37, no. 1, pp. 6572, 2005.

[66] N. Jha, D. P. Mondal, J. Dutta Majumdar, A. Badkul, A. K. Jha, and A. K. Khare, "Highly porous open cell Ti-foam using $\mathrm{NaCl}$ as temporary space holder through powder metallurgy route," Materials and Design, vol. 47, pp. 810-819, 2013.

[67] D. S. Li, Y. P. Zhang, X. Ma, and X. P. Zhang, "Space-holder engineered porous NiTi shape memory alloys with improved pore characteristics and mechanical properties," Journal of Alloys and Compounds, vol. 474, pp. 1-5, 2009.

[68] M. C. Saha, H. Mahfuz, U. K. Chakravarty, M. Uddin, M. E. Kabir, and S. Jeelani, "Effect of density, microstructure, and strain rate on compression behavior of polymeric foams," Materials Science and Engineering A, vol. 406, no. 1-2, pp. 328336, 2005. 
[69] N. Tuncer, G. Arslan, E. Maire, and L. Salvo, "Investigation of spacer size effect on architecture and mechanical properties of porous titanium," Materials Science and Engineering A, vol. 530, no. 1, pp. 633-642, 2011.

[70] R. E. Raj and B. S. S. Daniel, "Structural and compressive property correlation of closed-cell aluminum foam," Journal of Alloys and Compounds, vol. 467, no. 1-2, pp. 550-556, 2009.

[71] H. Shen, H. Li, and L. C. Brinson, "Effect of microstructural configurations on the mechanical responses of porous titanium: a numerical design of experiment analysis for orthopedic applications," Mechanics of Materials, vol. 40, no. 9, pp. 708-720, 2008.

[72] M. Nakai, M. Niinomi, T. Akahori et al., "Development of biomedical porous titanium filled with medical polymer by insitu polymerization of monomer solution infiltrated into pores," Journal of the Mechanical Behavior of Biomedical Materials, vol. 3, no. 1, pp. 41-50, 2010.

[73] C. Bural, E. Aktaş, G. Deniz, Y. Ünlüçerçi, N. Kizilcan, and G. Bayraktar, "Effect of post-polymerization heat-treatments on degree of conversion, leaching residual MMA and in vitro cytotoxicity of autopolymerizing acrylic repair resin," Dental Materials, vol. 27, no. 11, pp. 1135-1143, 2011.

[74] M. A. Pemberton and B. S. Lohmann, "Risk Assessment of residual monomer migrating from acrylic polymers and causing Allergic Contact Dermatitis during normal handling and use," Regulatory Toxicology and Pharmacology, vol. 69, no. 3, pp. 467-475, 2014.

[75] I.-H. Oh, N. Nomura, N. Masahashi, and S. Hanada, "Mechanical properties of porous titanium compacts prepared by powder sintering," Scripta Materialia, vol. 49, no. 12, pp. 1197-1202, 2003.

[76] A. Laptev, O. Vyal, M. Bram, H. P. Buchkremer, and D. Stöver, "Green strength of powder compacts provided for production of highly porous titanium parts," Powder Metallurgy, vol. 48, no. 4, pp. 358-364, 2005.

[77] Z. Esen and Ş. Bor, "Processing of titanium foams using magnesium spacer particles," Scripta Materialia, vol. 56, no. 5, pp. 341-344, 2007.

[78] M. I. Lifland and K. Okazaki, "Properties of titanium dental implants produced by electro-discharge compaction," Clinical Materials, vol. 17, no. 4, pp. 203-209, 1994.

[79] A. Ibrahim, F. Zhang, E. Otterstein, and E. Burkel, "Processing of porous $\mathrm{Ti}$ and $\mathrm{Ti} 5 \mathrm{Mn}$ foams by spark plasma sintering," Materials and Design, vol. 32, no. 1, pp. 146-153, 2011.

[80] C. Y. Tang, C. T. Wong, L. N. Zhang et al., "In situ formation of $\mathrm{Ti}$ alloy/TiC porous composites by rapid microwave sintering of Ti6Al4V/MWCNTs powder," Journal of Alloys and Compounds, vol. 557, pp. 67-72, 2013.

[81] L.-J. Chen, T. Li, Y.-M. Li, H. He, and Y.-H. Hu, "Porous titanium implants fabricated by metal injection molding," Transactions of Nonferrous Metals Society of China (English Edition), vol. 19, no. 5, pp. 1174-1179, 2009.

[82] B. Yuan, X. P. Zhang, C. Y. Chung, M. Q. Zeng, and M. $\mathrm{Zhu}$, "A comparative study of the porous TiNi shape-memory alloys fabricated by three different processes," Metallurgical and Materials Transactions A, vol. 37, no. 3, pp. 755-761, 2006.

[83] B. Yuan, C. Y. Chung, and M. Zhu, "Microstructure and martensitic transformation behavior of porous NiTi shape memory alloy prepared by hot isostatic pressing processing," Materials Science and Engineering A, vol. 382, no. 1-2, pp. 181-187, 2004.

[84] A. W. Nugroho, G. Leadbeater, and I. J. Davies, "Processing of a porous titanium alloy from elemental powders using a solid state isothermal foaming technique," Journal of Materials Science: Materials in Medicine, vol. 21, no. 12, pp. 3103-3107, 2010.

[85] S.-W. Yook, H.-E. Kim, and Y.-H. Koh, "Fabrication of porous titanium scaffolds with high compressive strength using camphene-based freeze casting," Materials Letters, vol. 63, no. 17, pp. 1502-1504, 2009.

[86] J. C. Li and D. C. Dunand, "Mechanical properties of directionally freeze-cast titanium foams," Acta Materialia, vol. 59, no. 1, pp. 146-158, 2011.

[87] S.-W. Yook, H.-D. Jung, C.-H. Park et al., "Reverse freeze casting: a new method for fabricating highly porous titanium scaffolds with aligned large pores," Acta Biomaterialia, vol. 8, no. 6, pp. 2401-2410, 2012.

[88] R. A. Ayers, D. E. Burkes, G. Gottoli et al., "Combustion synthesis of porous biomaterials," Journal of Biomedical Materials Research Part A, vol. 81, no. 3, pp. 634-643, 2007.

[89] B. Neirinck, T. Mattheys, A. Braem, J. Fransaer, O. Van Der Biest, and J. Vleugels, "Preparation of titanium foams by slip casting of particle stabilized emulsions," Advanced Engineering Materials, vol. 11, no. 8, pp. 633-636, 2009.

[90] K. A. Erk, D. C. Dunand, and K. R. Shull, "Titanium with controllable pore fractions by thermoreversible gelcasting of $\mathrm{TiH}_{2}$," Acta Materialia, vol. 56, no. 18, pp. 5147-5157, 2008.

[91] C. Zhao, X. Zhu, K. Liang et al., "Osteoinduction of porous titanium: a comparative study between acid-alkali and chemicalthermal treatments," Journal of Biomedical Materials Research Part B Applied Biomaterials, vol. 95, no. 2, pp. 387-396, 2010.

[92] G. He, P. Liu, and Q. Tan, "Porous titanium materials with entangled wire structure for load-bearing biomedical applications," Journal of the Mechanical Behavior of Biomedical Materials, vol. 5, no. 1, pp. 16-31, 2012.

[93] I. V. Shishkovsky, M. V. Kuznetsov, and Y. G. Morozov, "Porous titanium and nitinol implants synthesized by SHS/SLS: microstructural and histomorphological analyses of tissue reactions," International Journal of Self-Propagating HighTemperature Synthesis, vol. 19, no. 2, pp. 157-167, 2010.

[94] P. Heinl, L. Müller, C. Körner, R. F. Singer, and F. A. Müller, "Cellular Ti-6Al-4V structures with interconnected macro porosity for bone implants fabricated by selective electron beam melting," Acta Biomaterialia, vol. 4, no. 5, pp. 1536-1544, 2008.

[95] B. V. Krishna, S. Bose, and A. Bandyopadhyay, "Low stiffness porous Ti structures for load-bearing implants," Acta Biomaterialia, vol. 3, no. 6, pp. 997-1006, 2007.

[96] C. M. Lee, C. P. Ju, and J. H. C. Lin, "Structure-property relationship of cast Ti-Nb alloys," Journal of Oral Rehabilitation, vol. 29, no. 4, pp. 314-322, 2002.

[97] M. Niinomi, D. Kuroda, K.-I. Fukunaga et al., "Corrosion wear fracture of new $\beta$ type biomedical titanium alloys," Materials Science and Engineering A, vol. 263, no. 2, pp. 193-199, 1999.

[98] P. Xue, Y. Li, K. Li, D. Zhang, and C. Zhou, "Superelasticity, corrosion resistance and biocompatibility of the Ti-19Zr$10 \mathrm{Nb}-1 \mathrm{Fe}$ alloy," Materials Science and Engineering C, vol. 50, pp. 179-186, 2015.

[99] P. Wang, Y. Feng, F. Liu, L. Wu, and S. Guan, "Microstructure and mechanical properties of $\mathrm{Ti}-\mathrm{Zr}-\mathrm{Cr}$ biomedical alloys," Materials Science and Engineering: C, vol. 51, pp. 148-152, 2015.

[100] Y. L. Zhou, M. Niinomi, and T. Akahori, "Effects of Ta content on Young's modulus and tensile properties of binary $\mathrm{Ti}-$ Ta alloys for biomedical applications," Materials Science and Engineering A, vol. 371, no. 1-2, pp. 283-290, 2004. 
[101] N. Sakaguchi, M. Niinomi, T. Akahori, J. Takeda, and H. Toda, "Effect of Ta content on mechanical properties of Ti-30NbXTa-5Zr," Materials Science and Engineering C, vol. 25, no. 3, pp. 370-376, 2005.

[102] D. R. N. Correa, F. B. Vicente, T. A. G. Donato, V. E. AranaChavez, M. A. R. Buzalaf, and C. R. Grandini, "The effect of the solute on the structure, selected mechanical properties, and biocompatibility of Ti-Zr system alloys for dental applications," Materials Science and Engineering C, vol. 34, pp. 354-359, 2014.

[103] A. L. R. Ribeiro, P. Hammer, L. G. Vaz, and L. A. Rocha, "Are new TiNbZr alloys potential substitutes of the Ti6Al4V alloy for dental applications? An electrochemical corrosion study," Biomedical Materials, vol. 8, no. 6, Article ID 065005, 2013.

[104] D. Raducanu, E. Vasilescu, V. D. Cojocaru et al., "Mechanical and corrosion resistance of a new nanostructured $\mathrm{Ti}-\mathrm{Zr}-\mathrm{Ta}-$ $\mathrm{Nb}$ alloy," Journal of the Mechanical Behavior of Biomedical Materials, vol. 4, no. 7, pp. 1421-1430, 2011.

[105] P. Gill, N. Munroe, C. Pulletikurthi, S. Pandya, and W. Haider, "Effect of manufacturing process on the biocompatibility and mechanical properties of Ti-30Ta alloy," Journal of Materials Engineering and Performance, vol. 20, no. 4-5, pp. 819-823, 2011.

[106] J. Xu, X.-J. Weng, X. Wang et al., "Potential use of porous titanium-niobium alloy in orthopedic implants: preparation and experimental study of its biocompatibility in vitro," PLoS ONE, vol. 8, no. 11, Article ID e79289, 2013.

[107] D. P. De Andrade, L. M. de Vasconcellos, I. C. Carvalho et al., "Titanium-35niobium alloy as a potential material for biomedical implants: in vitro study," Materials Science and Engineering C, vol. 56, pp. 538-544, 2015.

[108] Y. Ikarashi, K. Toyoda, E. Kobayashi et al., "Improved biocompatibility of titanium-zirconium (Ti-Zr) alloy: tissue reaction and sensitization to $\mathrm{Ti}-\mathrm{Zr}$ alloy compared with pure $\mathrm{Ti}$ and $\mathrm{Zr}$ in rat implantation study," Journal of the Japan Institute of Metals, vol. 71, no. 4, pp. 395-401, 2007.

[109] S. Sista, C. Wen, P. D. Hodgson, and G. Pande, "The influence of surface energy of titanium-zirconium alloy on osteoblast cell functions in vitro," Journal of Biomedical Materials Research Part A, vol. 97, no. 1, pp. 27-36, 2011.

[110] A. Inoue, "High strength bulk amorphous alloys with low critical cooling rates (overview)," Materials Transactions, JIM, vol. 36, no. 7, pp. 866-875, 1995.

[111] W. Klement, R. H. Willens, and P. Duwez, "Non-crystalline Structure in Solidified Gold-Silicon Alloys," Nature, vol. 187, pp. 869-870, 1960.

[112] A. Inoue, "Stabilization of metallic supercooled liquid and bulk amorphous alloys," Acta Materialia, vol. 48, no. 1, pp. 279-306, 2000.

[113] A. Inoue and A. Takeuchi, "Recent development and application products of bulk glassy alloys," Acta Materialia, vol. 59, no. 6, pp. 2243-2267, 2011.

[114] A. Inoue, "Bulk amorphous alloys with soft and hard magnetic properties," Materials Science and Engineering A, vol. 226-228, pp. 357-363, 1997.

[115] A. Inoue, T. Zhang, and T. Masumoto, "Glass-forming ability of alloys," Journal of Non-Crystalline Solids, vol. 156-158, no. 2, pp. 473-480, 1993.

[116] Y. J. Huang, J. Shen, J. F. Sun, and X. B. Yu, "A new Ti-Zr-Hf-CuNi-Si-Sn bulk amorphous alloy with high glass-forming ability," Journal of Alloys and Compounds, vol. 427, no. 1-2, pp. 171-175, 2007.
[117] M. X. Xia, C. L. Ma, H. X. Zheng, and J. G. Li, "Preparation and crystallization of $\mathrm{Ti}_{53} \mathrm{Cu}_{27} \mathrm{Ni}_{12} \mathrm{Zr}_{3} \mathrm{Al}_{7} \mathrm{Si}_{3} \mathrm{~B}_{1}$ bulk metallic glass with wide supercooled liquid region," Materials Science and Engineering A, vol. 390, no. 1-2, pp. 372-375, 2005.

[118] C. Ma, S. Ishihara, H. Soejima, N. Nishiyama, and A. Inoue, "Formation of new Ti-based metallic glassy alloys," Materials Transactions, vol. 45, no. 5, pp. 1802-1806, 2004.

[119] Y. C. Kim, D. H. Bae, W. T. Kim, and D. H. Kim, "Glass forming ability and crystallization behavior of Ti-based amorphous alloys with high specific strength," Journal of Non-Crystalline Solids, vol. 325, no. 1-3, pp. 242-250, 2003.

[120] Y.-C. Kim, W. T. Kim, and D.-H. Kim, "Glass forming ability and crystallization behavior in amorphous $\mathrm{Ti}_{50} \mathrm{Cu}_{32-\mathrm{x}} \mathrm{Ni}_{15} \mathrm{Sn}_{3} \mathrm{Be}_{\mathrm{x}}$ $(\mathrm{x}=0,1,3,7)$ alloys," Materials Transactions, vol. 43, no. 5, pp. 1243-1246, 2002.

[121] T. Zhang, A. Inoue, and T. Masumoto, "Amorphous (Ti, Zr, Hf)$\mathrm{Ni}-\mathrm{Cu}$ ternary alloys with a wide supercooled liquid region," Materials Science and Engineering A, vol. 181-82, no. 2, pp. 14231426, 1994.

[122] G. Duan, A. Wiest, M. L. Lind, A. Kahl, and W. L. Johnson, "Lightweight Ti-based bulk metallic glasses excluding late transition metals," Scripta Materialia, vol. 58, no. 6, pp. 465-468, 2008.

[123] J. M. Park, G. Wang, S. Pauly, N. Mattern, D. H. Kim, and J. Eckert, "Ductile Ti-based bulk metallic glasses with high specific strength," Metallurgical and Materials Transactions A: Physical Metallurgy and Materials Science, vol. 42, no. 6, pp. 1456-1462, 2011.

[124] Y. C. Kim, J. M. Park, J. K. Lee, D. H. Bae, W. T. Kim, and D. H. Kim, "Amorphous and icosahedral phases in $\mathrm{Ti}-\mathrm{Zr}-\mathrm{Cu}-\mathrm{Ni}-\mathrm{Be}$ alloys," Materials Science and Engineering A, vol. 375-377, no. 1-2, pp. 749-753, 2004.

[125] K. Amiya, N. Nishiyama, A. Inoue, and T. Masumoto, "Mechanical strength and thermal stability of Ti-based amorphous alloys with large glass-forming ability," Materials Science and Engineering A, vol. 179-180, no. 1, pp. 692-696, 1994.

[126] X. H. Lin and W. L. Johnson, "Formation of Ti-Zr-Cu-Ni bulk metallic glasses," Journal of Applied Physics, vol. 78, no. 11, pp. 6514-6519, 1995.

[127] C. Ma, H. Soejima, S. Ishihara, K. Amiya, N. Nishiyama, and A. Inoue, "New Ti-based bulk glassy alloys with high glassforming ability and superior mechanical properties," Materials Transactions, vol. 45, no. 11, pp. 3223-3227, 2004.

[128] F. Qin, X. Wang, A. Kawashima, S. Zhu, H. Kimura, and A. Inoue, "Corrosion behavior of Ti-based metallic glasses," Materials Transactions, vol. 47, no. 8, pp. 1934-1937, 2006.

[129] Y. Zhang, Z.-W. Zhang, Y.-M. Xie et al., "Toxicity of nickel ions and comprehensive analysis of nickel ion-associated gene expression profiles in THP-1 cells," Molecular Medicine Reports, vol. 12, no. 3, pp. 3273-3278, 2015.

[130] G. L. Finch, R. J. Verburg, J. A. Mewhinney, A. F. Eidson, and M. D. Hoover, "The effect of beryllium compound solubility on in vitro canine alveolar macrophage cytotoxicity," Toxicology Letters, vol. 41, no. 2, pp. 97-105, 1988.

[131] S. L. Zhu, X. M. Wang, F. X. Qin, and A. Inoue, "A new Ti-based bulk glassy alloy with potential for biomedical application," Materials Science and Engineering A, vol. 459, no. 1-2, pp. 233237, 2007.

[132] S. L. Zhu, X. M. Wang, F. X. Qin, M. Yoshimura, and A. Inoue, "New TiZrCuPd quaternary bulk glassy alloys with potential of biomedical applications," Materials Transactions, vol. 48, no. 9, pp. 2445-2448, 2007. 
[133] G. Xie, F. Qin, S. Zhu, and A. Inoue, "Ni-free Ti-based bulk metallic glass with potential for biomedical applications produced by spark plasma sintering," Intermetallics, vol. 29, pp. 99-103, 2012.

[134] S. L. Zhu, X. M. Wang, and A. Inoue, "Glass-forming ability and mechanical properties of Ti-based bulk glassy alloys with large diameters of up to $1 \mathrm{~cm}$," Intermetallics, vol. 16, no. 8, pp. 1031$1035,2008$.

[135] S. Zhu, G. Xie, F. Qin, X. Wang, and A. Inoue, "Effect of minor Sn additions on the formation and properties of TiCuZrPd bulk glassy alloy," Materials Transactions, vol. 53, no. 3, pp. 500-503, 2012.

[136] J.-J. Oak, D. V. Louzguine-Luzgin, and A. Inoue, "Fabrication of $\mathrm{Ni}$-free Ti-based bulk-metallic glassy alloy having potential for application as biomaterial, and investigation of its mechanical properties, corrosion, and crystallization behavior," Journal of Materials Research, vol. 22, no. 5, pp. 1346-1353, 2007.

[137] C. L. Qin, J. J. Oak, N. Ohtsu, K. Asami, and A. Inoue, "XPS study on the surface films of a newly designed Ni-free Ti-based bulk metallic glass," Acta Materialia, vol. 55, no. 6, pp. 20572063, 2007.

[138] S. Pang, Y. Liu, H. Li, L. Sun, Y. Li, and T. Zhang, "New Ti-based $\mathrm{Ti}-\mathrm{Cu}-\mathrm{Zr}-\mathrm{Fe}-\mathrm{Sn}-\mathrm{Si}-\mathrm{Ag}$ bulk metallic glass for biomedical applications," Journal of Alloys and Compounds, vol. 625, pp. 323-327, 2015.

[139] T. Wang, Y. D. Wu, J. J. Si, Y. H. Cai, X. H. Chen, and X. D. Hui, "Novel Ti-based bulk metallic glasses with superior plastic yielding strength and corrosion resistance," Materials Science and Engineering: A, vol. 642, pp. 297-303, 2015.

[140] S. L. Zhu, X. M. Wang, F. X. Qin, M. Yoshimura, and A. Inoue, "Effects of Si addition on the glass-forming ability, glass transition and crystallization behaviors of $\mathrm{Ti}_{40} \mathrm{Zr}_{10} \mathrm{Cu}_{36} \mathrm{Pd}_{14}$ bulk glassy alloy," Intermetallics, vol. 16, no. 5, pp. 609-614, 2008.

[141] F. X. Qin, X. M. Wang, G. Q. Xie, and A. Inoue, "Distinct plastic strain of Ni-free Ti-Zr-Cu-Pd-Nb bulk metallic glasses with potential for biomedical applications," Intermetallics, vol. 16, no. 8, pp. 1026-1030, 2008.

[142] F. X. Qin, G. Q. Xie, Z. H. Dan, and A. Inoue, "Effect of minor addition of noble elements on microstructure and mechanical properties of Ti-based bulk metallic glasses," Applied Mechanics and Materials, vol. 148-149, pp. 241-244, 2011.

[143] J. Fornell, E. Pellicer, N. Van Steenberge et al., "Improved plasticity and corrosion behavior in $\mathrm{Ti}-\mathrm{Zr}-\mathrm{Cu}-\mathrm{Pd}$ metallic glass with minor additions of $\mathrm{Nb}$ : an alloy composition intended for biomedical applications," Materials Science and Engineering A, vol. 559, pp. 159-164, 2013.

[144] G. Wang, H. B. Fan, Y. J. Huang, J. Shen, and Z. H. Chen, "A new TiCuHfSi bulk metallic glass with potential for biomedical applications," Materials \& Design, vol. 54, pp. 251-255, 2014.

[145] Z. P. Lu, J. Shen, D. W. Xing, J. F. Sun, and C. T. Liu, "Binary eutectic clusters and glass formation in ideal glass-forming liquids," Applied Physics Letters, vol. 89, no. 7, Article ID 071910, pp. 2004-2007, 2006.

[146] J.-J. Oak, G.-W. Hwang, Y.-H. Park, H. Kimura, S.-Y. Yoon, and A. Inoue, "Characterization of surface properties, osteoblast cell culture in vitro and processing with flow-viscosity of Nifree Ti-based bulk metallic glass for biomaterials," Journal of Biomechanical Science and Engineering, vol. 4, no. 3, pp. 384391, 2009.

[147] Y. B. Wang, H. F. Li, Y. Cheng, Y. F. Zheng, and L. Q. Ruan, "In vitro and in vivo studies on Ti-based bulk metallic glass as potential dental implant material," Materials Science and Engineering C, vol. 33, no. 6, pp. 3489-3497, 2013.

[148] F. X. Qin, X. M. Wang, T. Wada, G. Q. Xie, K. Asami, and A. Inoue, "Formation of hydroxyapatite on Ti-coated $\mathrm{Ti}-\mathrm{Zr}$-Cu-Pd bulk metallic glass," Materials Transactions, vol. 50, no. 3, pp. 605-609, 2009.

[149] F. X. Qin, G. Q. Xie, X. M. Wang et al., "Microstructure and electrochemical properties of PVD TiN, (Ti, Al) N-coated Tibased bulk metallic glasses," Materials Transactions, vol. 50, no. 6, pp. 1313-1317, 2009.

[150] J.-J. Oak, A. Inoue, K. V. Rao, H.-H. Chun, and Y. H. Park, "Surface modified Ti based metallic glasses for bioactivation by electrochemical treatment technique," Journal of Alloys and Compounds, vol. 615, no. 1, pp. S136-S141, 2014.

[151] Y. Okazaki, S. Rao, Y. Ito, and T. Tateishi, "Corrosion resistance, mechanical properties, corrosion fatigue strength and cytocompatibility of new Ti alloys without $\mathrm{Al}$ and V,' Biomaterials, vol. 19, no. 13, pp. 1197-1215, 1998.

[152] X. Liu, P. K. Chu, and C. Ding, "Surface modification of titanium, titanium alloys, and related materials for biomedical applications," Materials Science and Engineering R: Reports, vol. 47, no. 3-4, pp. 49-121, 2004.

[153] B. Kasemo, "Biocompatibility of titanium implants: surface science aspects," The Journal of Prosthetic Dentistry, vol. 49, no. 6, pp. 832-837, 1983.

[154] N. K. Kuromoto, R. A. Simão, and G. A. Soares, “Titanium oxide films produced on commercially pure titanium by anodic oxidation with different voltages," Materials Characterization, vol. 58, no. 2, pp. 114-121, 2007.

[155] L. Le Guéhennec, A. Soueidan, P. Layrolle, and Y. Amouriq, "Surface treatments of titanium dental implants for rapid osseointegration," Dental Materials, vol. 23, no. 7, pp. 844-854, 2007.

[156] Y.-T. Sul, C. B. Johansson, Y. Jeong, and T. Albrektsson, "The electrochemical oxide growth behaviour on titanium in acid and alkaline electrolytes," Medical Engineering and Physics, vol. 23, no. 5, pp. 329-346, 2001.

[157] Z. X. Chen, Y. Takao, W. X. Wang, T. Matsubara, and L. M. Ren, "Surface characteristics and in vitro biocompatibility of titanium anodized in a phosphoric acid solution at different voltages," Biomedical Materials, vol. 4, no. 6, Article ID 065003, 2009.

[158] M. Uchida, H. M. Kim, T. Kokubo, and T. Nakamura, "Apatiteforming ability of titania gels with different structures," in Proceedings of the Symposium and Annual Meeting of International Society for Ceramics in Medicine (BIOCERAMICS '19), vol. 12, pp. 149-152, 1999.

[159] B. Yang, M. Uchida, H.-M. Kim, X. Zhang, and T. Kokubo, "Preparation of bioactive titanium metal via anodic oxidation treatment," Biomaterials, vol. 25, no. 6, pp. 1003-1010, 2004.

[160] X. Cui, H.-M. Kim, M. Kawashita et al., "Preparation of bioactive titania films on titanium metal via anodic oxidation," Dental Materials, vol. 25, no. 1, pp. 80-86, 2009.

[161] C. Leinenbach and D. Eifler, "Influence of oxidation treatment on fatigue and fatigue-induced damage of commercially pure titanium," Acta Biomaterialia, vol. 5, no. 7, pp. 2810-2819, 2009.

[162] J. R. Creighton and P. Ho, "Introduction to chemical vapor deposition (CVD)," in Chemical Vapor Deposition, chapter 1, 2001.

[163] M. Ohring, The Materials Science of Thin Films: Deposition and Structure, Academic Press, New York, NY, USA, 2nd edition, 1992. 
[164] Y. Hayashi and G. Nakayama, "Corrosion behavior in subcritical and supercritical water containing sodium chloride," Corrosion Engineering, Science and Technology, vol. 31, no. 6, pp. 491-494, 2002.

[165] H.-G. Kim, S.-H. Ahn, J.-G. Kim, S. J. Park, and K.-R. Lee, "Corrosion performance of diamond-like carbon (DLC)-coated Ti alloy in the simulated body fluid environment," Diamond and Related Materials, vol. 14, no. 1, pp. 35-41, 2005.

[166] S. K. Kim, J. B. Lee, J. Y. Koak et al., "An abutment screw loosening study of a Diamond Like Carbon-coated CP titanium implant," Journal of Oral Rehabilitation, vol. 32, no. 5, pp. 346350, 2005.

[167] J.-G. Kim, K.-R. Lee, and S.-J. Yang, "Wear-corrosion performance of Si-DLC coatings on Ti-6A1-4V substrate," Journal of Biomedical Materials Research Part A, vol. 86, no. 1, pp. 41-47, 2008.

[168] R. Hauert, C. V. Falub, G. Thorwarth et al., "Retrospective lifetime estimation of failed and explanted diamond-like carbon coated hip joint balls," Acta Biomaterialia, vol. 8, no. 8, pp. 31703176, 2012.

[169] R. Butter, M. Allen, L. Chandra, A. H. Lettington, and N. Rushton, "In vitro studies of DLC coatings with silicon intermediate layer," Diamond and Related Materials, vol. 4, no. 5-6, pp. 857861, 1995.

[170] L. Chandra, M. Allen, R. Butter, N. Rushton, A. H. Lettington, and T. W. Clyne, "The effect of biological fluids on the adhesion of diamond-like carbon films to metallic substrates," Diamond and Related Materials, vol. 4, no. 5-6, pp. 852-856, 1995.

[171] J. Konefał-Góral, A. Małek, S. Kluska et al., "Silicon carbonitride layers deposited on titanium and polyurethane by PACVD method," Materials Science, vol. 31, no. 3, pp. 476-483, 2013.

[172] Y. Zhu, W. Wang, X. Jia, T. Akasaka, S. Liao, and F. Watari, "Deposition of TiC film on titanium for abrasion resistant implant material by ion-enhanced triode plasma CVD," Applied Surface Science, vol. 262, pp. 156-158, 2012.

[173] B. Al-Nawas, U. Hangen, H. Duschner, F. Krummenauer, and W. Wagner, "Turned, machined versus double-etched dental implants in vivo," Clinical Implant Dentistry and Related Research, vol. 9, no. 2, pp. 71-78, 2007.

[174] E. M. Pinholt, "Brånemark and ITI dental implants in the human bone-grafted maxilla: a comparative evaluation," Clinical Oral Implants Research, vol. 14, no. 5, pp. 584-592, 2003.

[175] K. Gotfredsen, L. Nimb, E. Hjörting-Hansen, J. S. Jensen, and A. Holmén, "Histomorphometric and removal torque analysis for $\mathrm{TiO}_{2}$-blasted titanium implants. An experimental study on dogs," Clinical Oral Implants Research, vol. 3, no. 2, pp. 77-84, 1992.

[176] A. Boukari, G. Francius, and J. Hemmerlé, "AFM force spectroscopy of the fibrinogen adsorption process onto dental implants," Journal of Biomedical Materials Research Part A, vol. 78, no. 3, pp. 466-472, 2006.

[177] A. Bagno and C. Di Bello, "Surface treatments and roughness properties of Ti-based biomaterials," Journal of Materials Science: Materials in Medicine, vol. 15, no. 9, pp. 935-949, 2004.

[178] H. Schliephake, D. Scharnweber, M. Dard, A. Sewing, A. Aref, and S. Roessler, "Functionalization of dental implant surfaces using adhesion molecules," Journal of Biomedical Materials Research-Part B: Applied Biomaterials, vol. 73, no. 1, pp. 88-96, 2005.

[179] J. Abdel-Haq, C. Z. Karabuda, V. Arisan, Z. Mutlu, and M. Kürkçü, "Osseointegration and stability of a modified sandblasted acid-etched implant: an experimental pilot study in sheep," Clinical Oral Implants Research, vol. 22, no. 3, pp. 265274, 2011.

[180] F. Schwarz, M. Wieland, Z. Schwartz et al., "Potential of chemically modified hydrophilic surface characteristics to support tissue integration of titanium dental implants," Journal of Biomedical Materials Research-Part B: Applied Biomaterials, vol. 88, no. 2, pp. 544-557, 2009.

[181] S.-M. Bang, H.-J. Moon, Y.-D. Kwon, J.-Y. Yoo, A. Pae, and I. K. Kwon, "Osteoblastic and osteoclastic differentiation on SLA and hydrophilic modified SLA titanium surfaces," Clinical Oral Implants Research, vol. 25, no. 7, pp. 831-837, 2014.

[182] N. P. Lang, G. E. Salvi, G. Huynh-Ba, S. Ivanovski, N. Donos, and D. D. Bosshardt, "Early osseointegration to hydrophilic and hydrophobic implant surfaces in humans," Clinical Oral Implants Research, vol. 22, no. 4, pp. 349-356, 2011.

[183] N. Donos, S. Hamlet, N. P. Lang et al., "Gene expression profile of osseointegration of a hydrophilic compared with a hydrophobic microrough implant surface," Clinical Oral Implants Research, vol. 22, no. 4, pp. 365-372, 2011.

[184] S. Patel, A. Butt, Q. Tao, D. Royhman, C. Sukotjo, and C. G. Takoudis, "Novel functionalization of Ti-V alloy and Ti-II using atomic layer deposition for improved surface wettability," Colloids and Surfaces B: Biointerfaces, vol. 115, pp. 280-285, 2014.

[185] Z. C. Karabuda, J. Abdel-Haq, and V. Arisan, "Stability, marginal bone loss and survival of standard and modified sand-blasted, acid-etched implants in bilateral edentulous spaces: a prospective 15-month evaluation," Clinical Oral Implants Research, vol. 22, no. 8, pp. 840-849, 2011.

[186] D. K. Pattanayak, S. Yamaguchi, T. Matsushita, T. Nakamura, and T. Kokubo, "Apatite-forming ability of titanium in terms of $\mathrm{pH}$ of the exposed solution," Journal of the Royal Society Interface, vol. 9, no. 74, pp. 2145-2155, 2012.

[187] H.-M. Kim, T. Himeno, M. Kawashita, J.-H. Lee, T. Kokubo, and T. Nakamura, "Surface potential change in bioactive titanium metal during the process of apatite formation in simulated body fluid," Journal of Biomedical Materials Research Part A, vol. 67, no. 4, pp. 1305-1309, 2003.

[188] H. Takadama, H.-M. Kim, T. Kokubo, and T. Nakamura, “TEMEDX study of mechanism of bonelike apatite formation on bioactive titanium metal in simulated body fluid," Journal of Biomedical Materials Research, vol. 57, no. 3, pp. 441-448, 2001.

[189] H. Takadama, H.-M. Kim, T. Kokubo, and T. Nakamura, "An Xray photoelectron spectroscopy study of the process of apatite formation on bioactive titanium metal," Journal of Biomedical Materials Research, vol. 55, no. 2, pp. 185-193, 2001.

[190] S. Yamaguchi, H. Takadama, T. Matsushita, T. Nakamura, and T. Kokubo, "Cross-sectional analysis of the surface ceramic layer developed on $\mathrm{Ti}$ metal by $\mathrm{NaOH}$-heat treatment and soaking in SBF,' Journal of the Ceramic Society of Japan, vol. 117, no. 1370, pp. 1126-1130, 2009.

[191] W. Q. Yan, T. Nakamura, M. Kobayashi, H.-M. Kim, F. Miyaji, and T. Kokubo, "Bonding of chemically treated titanium implants to bone," Journal of Biomedical Materials Research, vol. 37, no. 2, pp. 267-275, 1997.

[192] R. S. Labow, E. Meek, and J. P. Santerre, "Alkali- and heat-treated porous titanium for orthopedic implants," Journal of Biomedical Materials Research, vol. 54, no. 2, pp. 198-208, 2001.

[193] M. Tsukanaka, K. Yamamoto, S. Fujibayashi et al., "Evaluation of bioactivity of alkali- and heat-treated titanium using fluorescent mouse osteoblasts," Journal of Bone and Mineral Metabolism, vol. 32, no. 6, pp. 660-670, 2013. 
[194] H.-M. Kim, F. Miyaji, T. Kokubo, and T. Nakamura, "Preparation of bioactive Ti and its alloys via simple chemical surface treatment," Journal of Biomedical Materials Research, vol. 32, no. 3, pp. 409-417, 1996.

[195] T. Ueno, N. Tsukimura, M. Yamada, and T. Ogawa, "Enhanced bone-integration capability of alkali- and heat-treated nanopolymorphic titanium in micro-to-nanoscale hierarchy," Biomaterials, vol. 32, no. 30, pp. 7297-7308, 2011.

[196] S. Nishiguchi, H. Kato, H. Fujita et al., "Enhancement of bonebonding strengths of titanium alloy implants by alkali and heat treatments," Journal of Biomedical Materials Research, vol. 48, no. 5, pp. 689-696, 1999.

[197] T. Kizuki, H. Takadama, T. Matsushita, T. Nakamura, and T. Kokubo, "Effect of Ca contamination on apatite formation in a Ti metal subjected to $\mathrm{NaOH}$ and heat treatments," Journal of Materials Science: Materials in Medicine, vol. 24, no. 3, pp. 635644, 2013.

[198] T. Kizuki, H. Takadama, T. Matsushita, T. Nakamura, and T. Kokubo, "Preparation of bioactive Ti metal surface enriched with calcium ions by chemical treatment," Acta Biomaterialia, vol. 6, no. 7, pp. 2836-2842, 2010.

[199] S. Yamaguchi, H. Takadama, T. Matsushita, T. Nakamura, and T. Kokubo, "Apatite-forming ability of Ti-15Zr-4Nb-4Ta alloy induced by calcium solution treatment," Journal of Materials Science: Materials in Medicine, vol. 21, no. 2, pp. 439-444, 2010.

[200] S. Yamaguchi, T. Kizuki, H. Takadama, T. Matsushita, T. Nakamura, and T. Kokubo, "Formation of a bioactive calcium titanate layer on gum metal by chemical treatment," Journal of Materials Science: Materials in Medicine, vol. 23, no. 4, pp. 873$883,2012$.

[201] A. Fukuda, M. Takemoto, T. Saito et al., "Bone bonding bioactivity of $\mathrm{Ti}$ metal and $\mathrm{Ti}-\mathrm{Zr}-\mathrm{Nb}-\mathrm{Ta}$ alloys with $\mathrm{Ca}$ ions incorporated on their surfaces by simple chemical and heat treatments," Acta Biomaterialia, vol. 7, no. 3, pp. 1379-1386, 2011.

[202] M. Tanaka, M. Takemoto, S. Fujibayashi et al., "Bone bonding ability of a chemically and thermally treated low elastic modulus Ti alloy: Gum metal," Journal of Materials Science: Materials in Medicine, vol. 25, no. 3, pp. 635-643, 2014.

[203] K. Kawanabe, K. Ise, K. Goto et al., "A new cementless total hip arthroplasty with bioactive titanium porous-coating by alkaline and heat treatment: average 4.8-year results," Journal of Biomedical Materials Research Part B: Applied Biomaterials, vol. 90, no. 1, pp. 476-481, 2009.

[204] K. So, A. Kaneuji, T. Matsumoto, S. Matsuda, and H. Akiyama, "Is the bone-bonding ability of a cementless total hip prosthesis enhanced by alkaline and heat treatments?" Clinical Orthopaedics and Related Research, vol. 471, no. 12, pp. 38473855, 2013.

[205] S. Fujibayashi, M. Takemoto, M. Neo et al., "A novel synthetic material for spinal fusion: a prospective clinical trial of porous bioactive titanium metal for lumbar interbody fusion," European Spine Journal, vol. 20, no. 9, pp. 1486-1495, 2011.

[206] H. Zhou, J. G. Lawrence, A. H. Touny, and S. B. Bhaduri, "Biomimetic coating of bisphosphonate incorporated CDHA on Ti6Al4V," Journal of Materials Science: Materials in Medicine, vol. 23, no. 2, pp. 365-374, 2012.

[207] N. Saran, R. Zhang, and R. E. Turcotte, "Osteogenic protein1 delivered by hydroxyapatite-coated implants improves bone ingrowth in extracortical bone bridging," Clinical Orthopaedics and Related Research, vol. 469, no. 5, pp. 1470-1478, 2011.
[208] S. Choi and W. L. Murphy, "Sustained plasmid DNA release from dissolving mineral coatings," Acta Biomaterialia, vol. 6, no. 9, pp. 3426-3435, 2010.

[209] T. Kokubo, D. K. Pattanayak, S. Yamaguchi et al., "Positively charged bioactive Ti metal prepared by simple chemical and heat treatments," Journal of the Royal Society Interface, vol. 7, supplement 5, pp. S503-S513, 2010.

[210] T. Kawai, M. Takemoto, S. Fujibayashi et al., "Bone-bonding properties of Ti metal subjected to acid and heat treatments," Journal of Materials Science: Materials in Medicine, vol. 23, no. 12, pp. 2981-2992, 2012.

[211] T. Kawai, M. Takemoto, S. Fujibayashi et al., "Osteoinduction on acid and heat treated porous Ti metal samples in canine muscle," PLoS ONE, vol. 9, no. 2, Article ID e88366, 2014.

[212] S. Yamaguchi, H. Takadama, T. Matsushita, T. Nakamura, and T. Kokubo, "Preparation of bioactive Ti-15Zr-4Nb-4Ta alloy from $\mathrm{HCl}$ and heat treatments after an $\mathrm{NaOH}$ treatment," Journal of Biomedical Materials Research Part A, vol. 97, no. 2, pp. 135-144, 2011.

[213] H. Ao, Y. Xie, H. Tan et al., "Improved hMSC functions on titanium coatings by type I collagen immobilization," Journal of Biomedical Materials Research Part A, vol. 102, no. 1, pp. 204214, 2014.

[214] P.-C. Chang, B.-Y. Liu, C.-M. Liu et al., "Bone tissue engineering with novel rhBMP2-PLLA composite scaffolds," Journal of Biomedical Materials Research A, vol. 81, no. 4, pp. 771-780, 2007.

[215] M. Dettin, A. Bagno, R. Gambaretto et al., "Covalent surface modification of titanium oxide with different adhesive peptides: surface characterization and osteoblast-like cell adhesion," Journal of Biomedical Materials Research-Part A, vol. 90, no. 1, pp. 35-45, 2009.

[216] Y.-J. Seol, Y.-J. Park, S.-C. Lee et al., "Enhanced osteogenic promotion around dental implants with synthetic binding motif mimicking bone morphogenetic protein (BMP)-2," Journal of Biomedical Materials Research Part A, vol. 77, no. 3, pp. 599-607, 2006.

[217] M. Morra, C. Cassinelli, L. Meda, M. Fini, G. Giavaresi, and R. Giardino, "Surface analysis and effects on interfacial bone microhardness of collagen-coated titanium implants: a rabbit model," International Journal of Oral and Maxillofacial Implants, vol. 20, no. 1, pp. 23-30, 2005.

[218] M. Morra, C. Cassinelli, G. Cascardo, D. Bollati, and R. Rodriguez Y Baena, "Multifunctional implant surfaces: Surface characterization and bone response to acid-etched Ti implants surface-modified by fibrillar collagen I," Journal of Biomedical Materials Research-Part A, vol. 94, no. 1, pp. 271-279, 2010.

[219] M. Morra, C. Cassinelli, G. Cascardo, D. Bollati, and R. R. Y. Baena, "Gene expression of markers of osteogenic differentiation of human mesenchymal cells on collagen I-modified microrough titanium surfaces," Journal of Biomedical Materials Research Part A, vol. 96, no. 2, pp. 449-455, 2011.

[220] P. Korn, M. C. Schulz, V. Hintze et al., "Chondroitin sulfate and sulfated hyaluronan-containing collagen coatings of titanium implants influence peri-implant bone formation in a minipig model," Journal of Biomedical Materials Research Part A, vol. 102, no. 7, pp. 2334-2344, 2014.

[221] A. T. Sverzut, G. E. Crippa, M. Morra, P. T. De Oliveira, M. M. Beloti, and A. L. Rosa, "Effects of type I collagen coating on titanium osseointegration: histomorphometric, cellular and molecular analyses," Biomedical Materials, vol. 7, no. 3, Article ID 035007, 2012. 
[222] M. Sartori, G. Giavaresi, A. Parrilli et al., "Collagen type I coating stimulates bone regeneration and osteointegration of titanium implants in the osteopenic rat," International Orthopaedics, vol. 39, no. 10, pp. 2041-2052, 2015.

[223] Y. J. Seol, Y. J. Park, S. C. Lee et al., "Enhanced osteogenic promotion around dental implants with synthetic binding motif mimicking bone morphogenetic protein (BMP)-2," Journal of Biomedical Materials Research A, vol. 81, pp. 771-780, 2007.

[224] M. Stigter, K. De Groot, and P. Layrolle, "Incorporation of tobramycin into biomimetic hydroxyapatite coating on titanium," Biomaterials, vol. 23, no. 20, pp. 4143-4153, 2002.

[225] M. Stigter, J. Bezemer, K. De Groot, and P. Layrolle, "Incorporation of different antibiotics into carbonated hydroxyapatite coatings on titanium implants, release and antibiotic efficacy," Journal of Controlled Release, vol. 99, no. 1, pp. 127-137, 2004.

[226] S. Radin, J. T. Campbell, P. Ducheyne, and J. M. Cuckler, "Calcium phosphate ceramic coatings as carriers of vancomycin," Biomaterials, vol. 18, no. 11, pp. 777-782, 1997.

[227] Y. Liu, X. Zhang, Y. Liu et al., "Bi-functionalization of a calcium phosphate-coated titanium surface with slow-release simvastatin and metronidazole to provide antibacterial activities and pro-osteodifferentiation capabilities," PLoS ONE, vol. 9, no. 5, Article ID e97741, 2014.

[228] H. Gollwitzer, K. Ibrahim, H. Meyer, W. Mittelmeier, R. Busch, and A. Stemberger, "Antibacterial poly(D,L-lactic acid) coating of medical implants using a biodegradable drug delivery technology," Journal of Antimicrobial Chemotherapy, vol. 51, no. 3, pp. 585-591, 2003.

[229] L. Zhang, J. Yan, Z. Yin et al., "Electrospun vancomycin-loaded coating on titanium implants for the prevention of implantassociated infections," International Journal of Nanomedicine, vol. 9, no. 1, pp. 3027-3036, 2014.

[230] L.-L. Li, L.-M. Wang, Y. Xu, and L.-X. Lv, "Preparation of gentamicin-loaded electrospun coating on titanium implants and a study of their properties in vitro," Archives of Orthopaedic and Trauma Surgery, vol. 132, no. 6, pp. 897-903, 2012.

[231] A. Ince, N. Schütze, C. Hendrich, F. Jakob, J. Eulert, and J. F. Löhr, "Effect of polyhexanide and gentamicin on human osteoblasts and endothelial cells," Swiss Medical Weekly, vol. 137, no. 9-10, pp. 139-145, 2007.

[232] A. Ince, N. Schütze, C. Hendrich, R. Thull, J. Eulert, and J. F. Löhr, "In vitro investigation of orthopedic titanium-coated and brushite-coated surfaces using human osteoblasts in the presence of gentamycin," Journal of Arthroplasty, vol. 23, no. 5, pp. 762-771, 2008.

[233] V. Antoci Jr., C. S. Adams, N. J. Hickok, I. M. Shapiro, and J. Parvizi, "Antibiotics for local delivery systems cause skeletal cell toxicity in vitro," Clinical Orthopaedics and Related Research, no. 462, pp. 200-206, 2007.

[234] M. C. Cortizo, T. G. Oberti, M. S. Cortizo, A. M. Cortizo, and M. A. Fernández Lorenzo De Mele, "Chlorhexidine delivery system from titanium/polybenzyl acrylate coating: evaluation of cytotoxicity and early bacterial adhesion," Journal of Dentistry, vol. 40, no. 4, pp. 329-337, 2012.

[235] M. E. Barbour, N. Gandhi, A. El-Turki, D. J. O'Sullivan, and D. C. Jagger, "Differential adhesion of Streptococcus gordonii to anatase and rutile titanium dioxide surfaces with and without functionalization with chlorhexidine," Journal of Biomedical Materials Research A, vol. 90, no. 4, pp. 993-998, 2009.
[236] L. G. Harris, L. Mead, E. Müller-Oberländer, and R. G. Richards, "Bacteria and cell cytocompatibility studies on coated medical grade titanium surfaces," Journal of Biomedical Materials Research Part A, vol. 78, no. 1, pp. 50-58, 2006.

[237] H. Aita, N. Hori, M. Takeuchi et al., "The effect of ultraviolet functionalization of titanium on integration with bone," Biomaterials, vol. 30, no. 6, pp. 1015-1025, 2009.

[238] A. M. Gallardo-Moreno, M. A. Pacha-Olivenza, L. Saldaña et al., "In vitro biocompatibility and bacterial adhesion of physico-chemically modified Ti6Al4V surface by means of UV irradiation," Acta Biomaterialia, vol. 5, no. 1, pp. 181-192, 2009.

[239] P.-H. Chua, K.-G. Neoh, E.-T. Kang, and W. Wang, "Surface functionalization of titanium with hyaluronic acid/chitosan polyelectrolyte multilayers and RGD for promoting osteoblast functions and inhibiting bacterial adhesion," Biomaterials, vol. 29, no. 10, pp. 1412-1421, 2008.

[240] L. Zhao, Y. Hu, D. Xu, and K. Cai, "Surface functionalization of titanium substrates with chitosan-lauric acid conjugate to enhance osteoblasts functions and inhibit bacteria adhesion," Colloids and Surfaces B: Biointerfaces, vol. 119, pp. 115-125, 2014.

[241] S. Mei, H. Wang, W. Wang et al., "Antibacterial effects and biocompatibility of titanium surfaces with graded silver incorporation in titania nanotubes," Biomaterials, vol. 35, no. 14, pp. 4255-4265, 2014.

[242] P. Zhang, Z. Zhang, and W. Li, "Antibacterial $\mathrm{TiO}_{2}$ coating incorporating silver nanoparticles by microarc oxidation and ion implantation," Journal of Nanomaterials, vol. 2013, Article ID 542878, 8 pages, 2013.

[243] L. Zhao, H. Wang, K. Huo et al., "Antibacterial nano-structured titania coating incorporated with silver nanoparticles," Biomaterials, vol. 32, no. 24, pp. 5706-5716, 2011.

[244] H. Cao, X. Liu, F. Meng, and P. K. Chu, "Biological actions of silver nanoparticles embedded in titanium controlled by microgalvanic effects," Biomaterials, vol. 32, no. 3, pp. 693-705, 2011.

[245] G. Nordberg and L. Gerhardsson, "Silver," in Handbook on Toxicity of Inorganic Compounds, H. G. Seiler, H. Sigel, and A. Sigel, Eds., pp. 619-624, Marcel Dekker, New York, NY, USA, 1988.

[246] N. Grier, "Silver and its compounds," in Disinfection, Sterilization, and Preservation, S. S. Block, Ed., Lea \& Febiger, Philadelphia, Pa, USA, 3rd edition, 1983.

[247] J. J. Blaker, A. R. Boccaccini, and S. N. Nazhat, "Thermal characterizations of silver-containing bioactive glass-coated sutures," Journal of Biomaterials Applications, vol. 20, no. 1, pp. 81-98, 2005.

[248] J. Auer, R. Berent, C.-K. Ng et al., "Early investigation of silvercoated Silzone heart valves prosthesis in 126 patients," Journal of Heart Valve Disease, vol. 10, no. 6, pp. 717-723, 2001.

[249] P. Gong, H. Li, X. He et al., "Preparation and antibacterial activity of $\mathrm{Fe}_{3} \mathrm{O}_{4} @ \mathrm{Ag}$ nanoparticles," Nanotechnology, vol. 18, no. 28, Article ID 285604, 2007.

[250] R. B. Thurman and C. H. P. Gerba, "The molecular mechanisms of copper and silver ion disinfection of bacteria and viruses," Critical Reviews in Environmental Control, vol. 18, no. 4, pp. 295315, 1988.

[251] Q. L. Feng, J. Wu, G. Q. Chen, F. Z. Cui, T. N. Kim, and J. O. Kim, "A mechanistic study of the antibacterial effect of silver ions on Escherichia coli and Staphylococcus aureus," Journal of Biomedical Materials Research, vol. 52, no. 4, pp. 662-668, 2000.

[252] R. M. Slawson, H. Lee, and J. T. Trevors, "Bacterial interactions with silver," Biology of Metals, vol. 3, no. 3-4, pp. 151-154, 1990. 
[253] G. Jin, H. Qin, H. Cao et al., "Synergist effects of dual Zn/Ag ion implantation in osteogenic activity and antibacterial ability of titanium," Biomaterials, vol. 35, no. 27, pp. 7699-7713, 2014.

[254] C. Della Valle, L. Visai, M. Santin et al., "A novel antibacterial modification treatment of titanium capable to improve osseointegration," International Journal of Artificial Organs, vol. 35, no. 10, pp. 864-875, 2012.

[255] A. Mombelli and F. Décaillet, "The characteristics of biofilms in peri-implant disease," Journal of Clinical Periodontology, vol. 38, no. 11, pp. 203-213, 2011.

[256] M. A. Massa, C. Covarrubias, M. Bittner et al., "Synthesis of new antibacterial composite coating for titanium based on highly ordered nanoporous silica and silver nanoparticles," Materials Science and Engineering C, vol. 45, pp. 146-153, 2014.

[257] L. Zhao, P. K. Chu, Y. Zhang, and Z. Wu, "Antibacterial coatings on titanium implants," Journal of Biomedical Materials Research Part B: Applied Biomaterials, vol. 91, no. 1, pp. 470-480, 2009.

[258] A. H. K. Chou, R. Z. LeGeros, Z. Chen, and Y. Li, "Antibacterial effect of zinc phosphate mineralized guided bone regeneration membranes," Implant Dentistry, vol. 16, no. 1, pp. 89-100, 2007.

[259] P. Petrini, C. R. Arciola, I. Pezzali et al., "Antibacterial activity of zinc modified titanium oxide surface," International Journal of Artificial Organs, vol. 29, no. 4, pp. 434-442, 2006.

[260] B. A. Sevinç and L. Hanley, "Antibacterial activity of dental composites containing zinc oxide nanoparticles," Journal of Biomedical Materials Research Part B: Applied Biomaterials, vol. 94, no. 1, pp. 22-31, 2010.

[261] Y. Li, W. Xiong, C. Zhang et al., "Enhanced osseointegration and antibacterial action of zinc-loaded titania-nanotube-coated titanium substrates: In vitro and in vivo studies," Journal of Biomedical Materials Research-Part A, vol. 102, no. 11, pp. 3939-3950, 2013.

[262] Y. Z. Wan, S. Raman, F. He, and Y. Huang, "Surface modification of medical metals by ion implantation of silver and copper," Vacuum, vol. 81, no. 9, pp. 1114-1118, 2007.

[263] Y. Z. Wan, G. Y. Xiong, H. Liang, S. Raman, F. He, and Y. Huang, "Modification of medical metals by ion implantation of copper," Applied Surface Science, vol. 253, no. 24, pp. 9426-9429, 2007. 

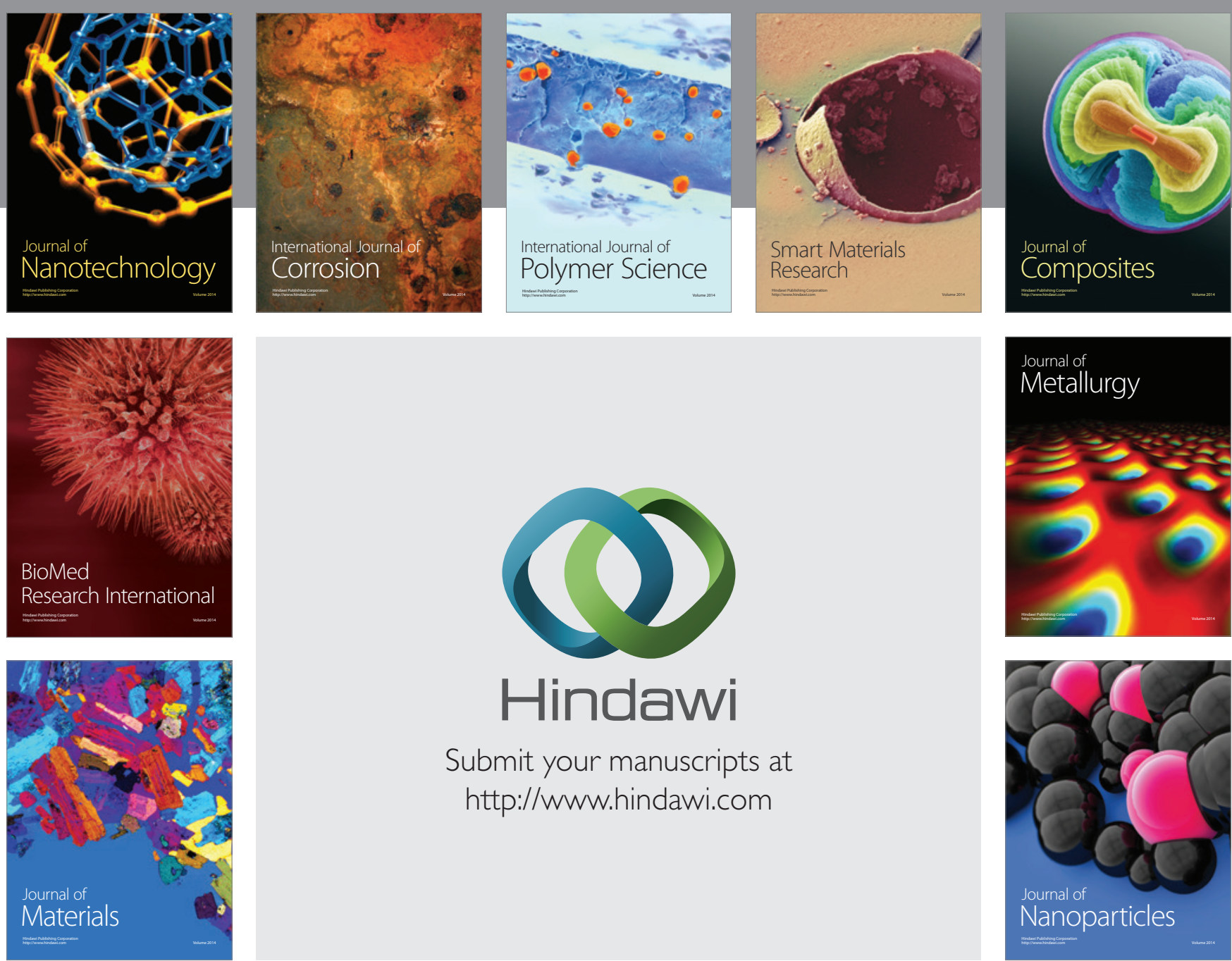

\section{Hindawi}

Submit your manuscripts at

http://www.hindawi.com

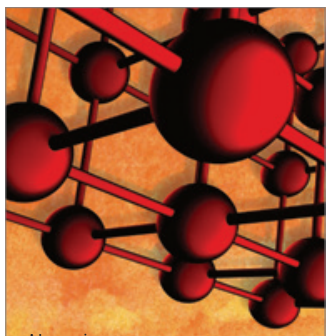

Materials Science and Engineering
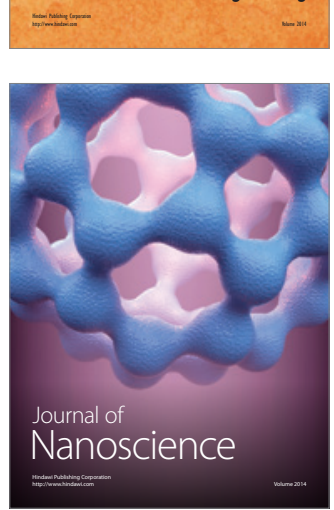
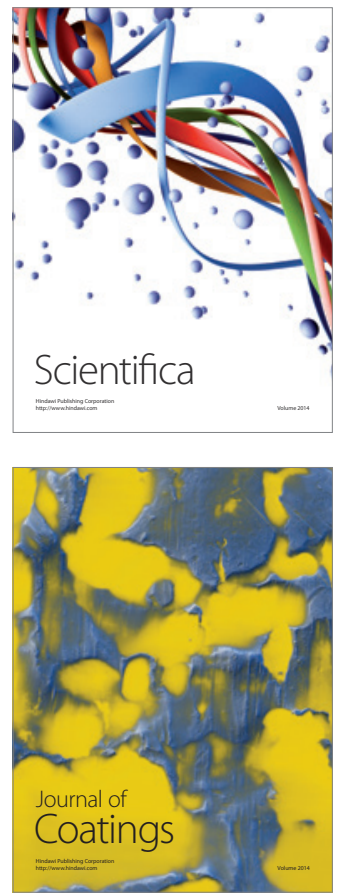
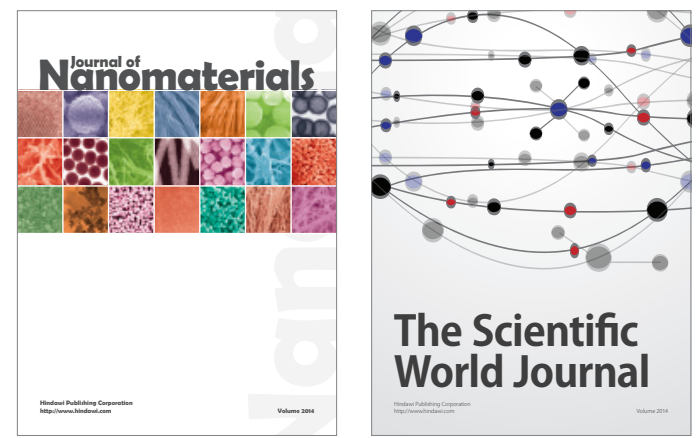

The Scientific World Journal
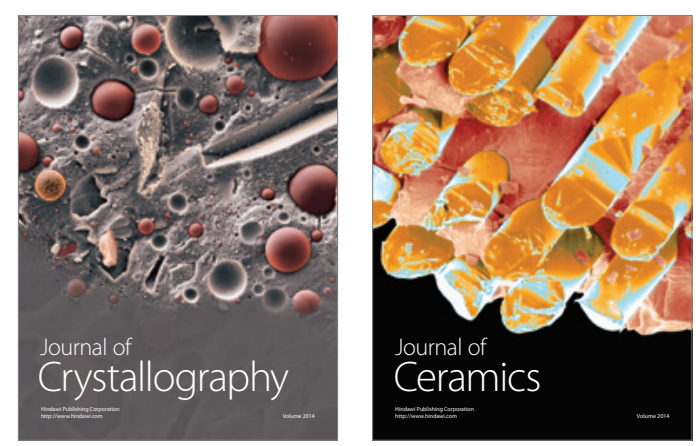
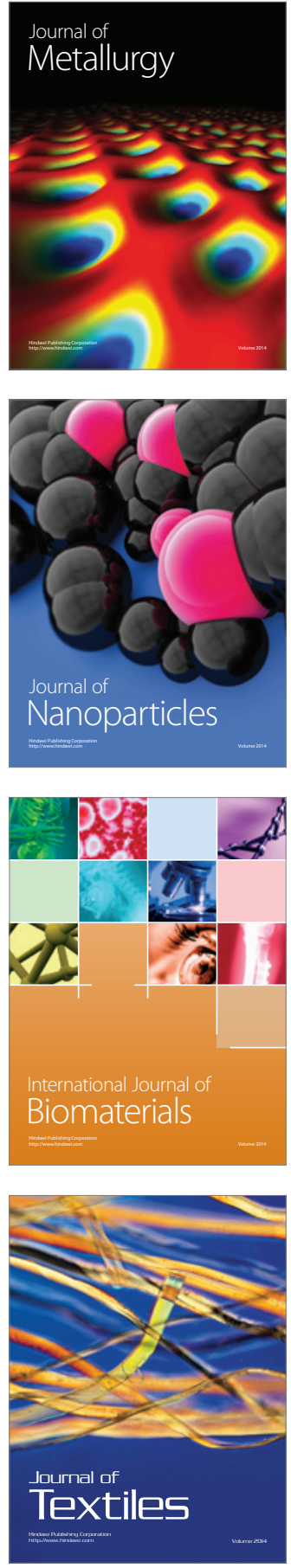